\title{
The Canonical Wnt Signaling Pathway Inhibits the Glucocorticoid Receptor Signaling Pathway in the Trabecular Meshwork
}

Chenna Kesavulu Sugali, ${ }^{*}$ Naga Pradeep Rayana, ${ }^{*}$ Jiannong Dai, ${ }^{*}$ Michael Peng, ${ }^{*}$ Sherri L. Harris, ${ }^{\dagger}$ Hannah C. Webber, Shaohui Liu, ${ }^{*}$ Stephan G. Dixon, ${ }^{*}$ Priyanka H. Parekh, ${ }^{*}$ Elizabeth A. Martin, ${ }^{*}$ Louis B. Cantor, ${ }^{*}$ Ronald L. Fellman, ${ }^{\dagger \neq}$ David G. Godfrey, ${ }^{\dagger \dagger}$ Michelle R. Butler, ${ }^{\dagger \dagger}$ Matthew E. Emanuel, ${ }^{\dagger \dagger}$ Davinder S. Grover, ${ }^{\dagger \ddagger}$ Oluwatosin U. Smith, ${ }^{\dagger \ddagger}$ Abbot F. Clark, Vijay Krishna Raghunathan, ${ }^{\S}$ and Weiming Mao* ${ }^{\mathbb{I}}$

From the Department of Ophthalmology, ${ }^{*}$ Eugene and Marilyn Glick Eye Institute, and the Department of Biochemistry and Molecular Biology, ${ }^{\llbracket}$ Indiana University School of Medicine, Indianapolis, Indiana; the Department of Pharmacology and Neuroscience, ${ }^{\dagger}$ North Texas Eye Research Institute, University of North Texas Health Science Center, Fort Worth, Texas; the Glaucoma Associates of Texas, ${ }^{\ddagger}$ Dallas, Texas; and the Department of Basic Sciences, ${ }^{\S}$ College of Optometry, University of Houston, Houston, Texas

Accepted for publication

February 22, 2021.

Address correspondence to Weiming Mao, Ph.D., Eugene and Marilyn Glick Eye Institute, Department of Ophthalmology, Department of Biochemistry and Molecular Biology, Indiana University School of Medicine, RM305v, 1160 W. Michigan St., Indianapolis, IN 46202. E-mail: weimmao@iu.edu.

\begin{abstract}
Glucocorticoid-induced glaucoma is a secondary open-angle glaucoma. About $40 \%$ of the general population may develop elevated intraocular pressure on prolonged glucocorticoid treatment secondary to damages in the trabecular meshwork (TM), a tissue that regulates intraocular pressure. Therefore, identifying the key molecules responsible for glucocorticoid-induced ocular hypertension is crucial. In this study, Dickkopf-related protein 1 (Dkk1), a canonical Wnt signaling inhibitor, was found to be elevated in the aqueous humor and TM of glaucoma patients. At the signaling level, Dkk1 enhanced glucocorticoid receptor (GR) signaling, whereas Dkk1 knockdown or Wnt signaling activators decreased GR signaling in human TM cells as indicated by luciferase assays. Similarly, activation of the GR signaling inhibited Wnt signaling. At the protein level, glucocorticoid-induced extracellular matrix was inhibited by Wnt activation using Wnt activators or Dkk1 knockdown in primary human TM cells. In contrast, inhibition of canonical Wnt signaling by $\beta$-catenin knockdown increased glucocorticoidinduced extracellular matrix proteins. At the physiological level, adenovirus-mediated Wnt3a expression decreased glucocorticoid-induced ocular hypertension in mouse eyes. In summary, Wnt and GR signaling inhibit each other in the TM, and canonical Wnt signaling activators may prevent the adverse effect of glucocorticoids in the eye. (Am J Pathol 2021, 191: 1020-1035; https://doi.org/10.1016/ j.ajpath.2021.02.018)
\end{abstract}

Glaucoma is the second leading cause of blindness worldwide. ${ }^{1}$ The primary risk factor of glaucoma is elevated intraocular pressure (IOP), ${ }^{2}$ which contributes to optic neuropathy, causing irreversible vision loss. Glucocorticoid-induced glaucoma (GIG) is a type of secondary open-angle glaucoma. Glucocorticoids (GCs) are the most commonly used antiinflammatory or immunosuppressive drugs in ocular and systemic diseases. Their pharmacologic effects are seen mainly via the glucocorticoid receptor signaling pathway. ${ }^{3}$ After binding to glucocorticoid receptors, GCs form glucocorticoidglucocorticoid receptor complexes, which translocate into the nucleus, where they bind to the glucocorticoid receptor-binding elements (GREs) and regulate gene expression. ${ }^{3}$ Long-term use of GCs, such as dexamethasone (Dex), is known to induce

Supported by the National Eye Institute (NEI) of the National Health Institute (NIH) under award number R01EY026962 (W.M.), Indiana University School of Medicine Showalter Scholarship (W.M.), BrightFocus Foundation G2017151 (W.M.), Cure Glaucoma Foundation (W.M.), the Indiana Clinical and Translational Sciences Institute funded, in part by award number UL1TR002529 from the NIH, National Center for Advancing Translational Sciences, Clinical and Translational Sciences Award (W.M.), partially by NEI R01EY030967 (A.F.C.), and NEI R01EY026048 (V.K.R.)

Disclosures: None declared. 
ocular hypertension in susceptible individuals. ${ }^{4-6}$ Studies show that about $40 \%$ of the general population is susceptible, referred to as GC responders. ${ }^{4-6}$ Interestingly, the responder rate could be as high as approximately $90 \%$ among patients with primary open-angle glaucoma (POAG). ${ }^{3,4,7-9}$

Pathologic changes in the trabecular meshwork (TM) of GIG eyes are similar to those of POAG eyes. ${ }^{3,10}$ The TM is the ocular tissue in the iridocorneal angle that is responsible for the drainage of most of the aqueous humor. ${ }^{11-13}$ Pathologic changes in the TM lead to increased outflow resistance and ocular hypertension in both GIG and POAG eyes. At the molecular level, GCs induce increased extracellular matrix (ECM) deposition, including fibronectin (FN), collagens, laminin, glycosaminoglycans, and elastin, in the TM. $^{3}$ They also increase TM ECM stiffness. ${ }^{14}$ At the cellular level, GCs induce the formation of cross-linked actin networks, ${ }^{15}$ induce endoplasmic reticulum stress, ${ }^{16}$ increase cell stiffness, ${ }^{14}$ as well as compromise the phagocytic function of the TM. ${ }^{17}$ Therefore, studying the underlying molecular mechanisms of GIG will contribute to the knowledge base of this disease and possibly POAG.

To determine the factors that contribute to GIG and differential GC responsiveness, we previously studied gene expression patterns between bovine TM cells from Dex-responder and nonresponder eyes and found that Dickkopf-related protein 1 (Dkk1), the canonical Wnt pathway inhibitor, was significantly increased in Dex-responder bovine TM using RNA sequencing. ${ }^{18}$ The Wnt signaling pathway is ubiquitous in development and pathophysiology, and has been extensively reviewed. ${ }^{19}$ Briefly, when Wnt ligands bind to their receptor Frizzled and coreceptor lipoprotein receptor-related protein $5 / 6$ (LRP5/6), the key transcriptional factor $\beta$-catenin accumulates in the cytosol and translocates into the nucleus. $\beta$-Catenin and its cotranscriptional factors bind to the T-cell factor/lymphoid enhancing factor (TCF/LEF) elements and change gene expression. Functional Wnt signaling has been reported in the TM. ${ }^{20,21}$ Raghunathan et $\mathrm{al}^{14}$ reported that Dex significantly elevated Dkk1 and secreted frizzled-related protein 1 (sFRP1) (another Wnt inhibitor) expression in ECM derived from primary human TM (HTM) cells. Interestingly, sFRP1 is evelated in POAG TM cells, ${ }^{21,22}$ and overexpression of both SFRP1 and Dkk1 can induce ocular hypertension in the mouse model, which can be blocked by Wnt activation. ${ }^{20,21}$ These findings suggested that canonical Wnt signaling plays a role in GIG. Therefore, the hypothesis that activation of canonical Wnt signaling ameliorates the TM changes associated with GCinduced ocular hypertension/GIG was tested.

\section{Materials and Methods}

\section{Aqueous Humor and Trabecular Meshwork Tissue Collection}

Aqueous humor samples were collected from cataract and/or glaucoma surgeries by glaucoma specialists at Glaucoma Associates of Texas (Dallas, TX). The cataract or glaucoma was determined based on clinical diagnoses by boardcertified glaucoma specialists. The glaucoma aqueous humor samples were collected from patients with a diagnosis of POAG with ocular hypertension. Normal tension glaucoma and other types of glaucoma aqueous humor samples were not included. After anterior chamber paracentesis, aqueous humor was aspirated using a Tuberculin syringe with a fine needle and caution was taken to avoid contamination by other body fluids. Samples were stored at $-20^{\circ} \mathrm{C}$ and transferred to the laboratory and kept at $-80^{\circ} \mathrm{C}$ before analysis.

Glaucomatous trabecular meshwork (GTM) tissues were collected from trabeculectomy procedures performed by glaucoma specialists at the Eugene and Marilyn Glick Eye Institute (Indianapolis, IN). The trabeculectomy block was fashioned with a number 67 Beaver blade and excised with Vanass scissors after direct visualization of the TM. The TM and scleral tissues were kept in saline at $4^{\circ} \mathrm{C}$ before being transferred to the laboratory. The entire tissue was fixed on the same day of collection in $4 \%$ paraformaldehyde in phosphatebuffered saline (PBS) at $4^{\circ} \mathrm{C}$ overnight.

Nonglaucomatous TM tissues were collected from human donor corneal rims (Saving Sight, St. Louis, MO; or Vision First, Indianapolis, IN) within a week postmortem. The tissues were processed similar to glaucomatous tissues.

Donor information is listed in Supplemental Table S1.

\section{Enzyme-Linked Immunosorbent Assay (ELISA)}

Dkk1 levels in human aqueous humor samples from both cataract and glaucoma + cataract patients were measured using the human Dkk1 Quantikine ELISA kit (R\&D Systems, Minneapolis, MN), according to the manufacturer's protocol. Samples were diluted using calibrator diluent RD518, and the plates were measured by the SpectraMax plate reader (Molecular Devices, San Jose, CA). The final concentration of Dkk1 is interpolated from plotting a fourparameter logistic curve fit and multiplied by dilution factors.

\section{Immunostaining of HTM Tissues}

Fixed glaucomatous and nonglaucomatous ocular tissues were embedded in paraffin, divided into sections ( $5 \mu \mathrm{m}$ thick), and transferred to glass slides. Slides were heated for 1 hour on a heated plate. Deparaffinization was performed by washing twice in xylene, twice in $100 \%$ ethanol, $95 \%$ ethanol, and $50 \%$ ethanol, each step for 3 minutes. Slides were soaked in running distilled water and then followed by antigen retrieval using the Tris-EDTA buffer $(10 \mathrm{mmol} / \mathrm{L}$ Tris base, $1 \mathrm{mmol} / \mathrm{L}$ EDTA solution, and $0.05 \%$ Tween 20, pH 9.0) and the 2100 Antigen retriever (Electron Microscopy Sciences, Hatfield, PA). Tissues were cooled to room temperature and exposed to Superblock TW Blocking Buffer in PBS (Thermofisher Scientific, Waltham, MA) for 60 minutes. The samples were incubated with primary rabbit anti-hDkk1 (1:250; catalog number ab61034; Abcam, Cambridge, MA) and mouse anti- $\beta$-tubulin 
(1:250; catalog number 86298T; Cell Signaling Technology, Danvers, MA) and then followed by the secondary antibody Alexa Fluor labeled goat anti-rabbit or goat anti-mouse Ig (Life Technologies, Carlsbad, CA). A no primary antibody control was also included to determine non-specific binding of the fluorophore-conjugated secondary antibody. Slides were mounted with the Prolong Gold mounting medium containing DAPI (Invitrogen, Carlsbad, CA). Images were taken using a Zeiss LSM700 Confocal Microscope (Zeiss, San Diego, CA).

To compare Dkk1 immunofluorescence intensity, the Dkk1 images and $\beta$-tubulin images were stacked using the ImageJ version 1.8.0_172 software Stacks tool (NIH, Bethesda, MD; https://imagej.nih.gov/ij, last accessed January 19, 2021; ImageJ was installed on a local computer). The TM tissue was manually selected using the Freehand selections tool. The fluorescent intensity of selected TM tissues was then measured in the stacked images so that the same shape, area, and location of the TM was measured for both Dkk1 and $\beta$-tubulin. The fluorescent intensity of Dkk1 staining was normalized to $\beta$-tubulin, and the ratios were compared between the glaucomatous group and the non-glaucomatous group.

\section{Human Trabecular Meshwork Cell Culture and Treatment}

Transformed human glaucomatous TM cell line (GTM3) and non-glaucomatous TM cell line (NTM5) ${ }^{23}$ were kind gifts from Alcon Research, Ltd (Fort Worth, TX). The GTM3 cells used in this study were no more than p28, and NTM5 cells were no more than p32. These two cell lines have been well characterized. ${ }^{24-26}$

Primary HTM cells generated from non-glaucomatous donors from eye banks were characterized based on Dex-induced myocilin expression, according to consensus (Supplemental Table S2). ${ }^{27}$ All TM cells were cultured in Opti-Modified Eagle's Minimum Essential Medium (Opti-MEM; Thermoscientific, Worcester, MA) containing $10 \%$ fetal bovine serum (Atlas Biologicals, Fort Collins, $\mathrm{CO}$ ) as well as $1 \%$ penicillin and streptomycin and $2 \mathrm{mmol} / \mathrm{L}$ glutamine (Thermoscientific) in an incubator with $5 \% \mathrm{CO}_{2}$ at $37^{\circ} \mathrm{C}$ (Thermoscientific). Primary HTM cells used in this study were no more than $\mathrm{p} 8$. Primary HTM cells were treated with $0.1 \%$ ethanol or 100 nmol/L Dex for 1 to 3 days. RNA was isolated using RNeasy (Qiagen, Frederick, MD) or Purelink (Thermoscientific) kit and used for cDNA synthesis [iScript (Bio-Rad, Hercules, CA) or a high-capacity cDNA reverse transcription kit (Applied Biosystems, Foster City, CA)] and real-time quantitative PCR [SsoAdvanced Universal SYBR Green Supermix (Bio-Rad) or PowerUp SYBR Green Master Mix kit (Applied Biosystems)] to determine myocilin induction using the CFX-96 realtime thermocycler (Bio-Rad). Primers were as follows: myocilin, 5'-GGAGGTAGCAAGGCTGAGAA-3' (forward) and 5'AGTTCCTGGAAGGCCAAAGT-3' (reverse), or 5'-TGTCC GCCAGGTTTTTGAGT-3' (forward) and 5'-TGGAAATAGAGGCTCCCCGA-3' (reverse); and glyceraldehyde-3- phosphate dehydrogenase, $5^{\prime}$-GGTGAAGGTCGGAGTCAA C-3' (forward) and $5^{\prime}$-CCATGGGTGGAATCATATTG-3' (reverse) ${ }^{28}$ The $\Delta \Delta \mathrm{Ct}$ method was used to compare gene expression.

Primary HTM cells were treated with or without $0.1 \%$ ethanol, $0.1 \%$ dimethyl sulfoxide (DMSO), $100 \mathrm{nmol} / \mathrm{L}$ Dex, and/or one of the glycogen synthase kinase (GSK) $3 \beta$ inhibitors ${ }^{29}$ including 6-bromoindirubin-3'-oxime (BIO), SB-216763 (SB), and CHIR99021 (CHIR) at 1, 10, or 5 $\mu \mathrm{mol} / \mathrm{L}$, respectively, for 72 hours in serum medium before the cells were harvested for Western immunoblotting.

\section{Western Immunoblotting}

Proteins from whole cell lysates were isolated using the M-PER buffer (Thermoscientific) with protease and phosphatase inhibitors. Protein concentrations were determined using the DC protein assay kit (Bio-Rad). Equal amounts of whole cell lysate proteins or equal volumes of conditioned medium were boiled in Laemmli SDS sample buffer (Alfa Aesar, Haverhill, MA), separated on 10\% SDS-PAGE gels, transferred to polyvinylidene difluoride membranes, blocked with 5\% dry milk in Tris-buffered saline with Tween 20 buffer, and probed with primary antibodies and corresponding secondary antibodies conjugated with horseradish peroxidase. The primary antibodies used in this study included rabbit anti- $\beta$-catenin (catalog number 8480S; 1:1000; Cell Signaling Technologies, Danvers, MA), mouse anti-FN (catalog number F0916; 1:1000; Sigma, St. Louis, MO), rabbit anti-collagen-I (catalog number ab215969; 1:1000; Abcam), rabbit anti-hDkk1 (catalog number 4687S; 1:1000; Cell Signaling Technologies), and rabbit anti-glyceraldehyde-3-phosphate dehydrogenase (catalog number 5174S; 1:1000; Cell Signaling Technology). Proteinantibody complexes were detected using Clarity Max Western ECL substrate (Bio-Rad) or SuperSignal West Femto Maximum Sensitivity Substrate (Thermoscientific) and visualized using the ChemiDoc Imaging Systems (Bio-Rad).

\section{Glucocorticoid Receptor Signaling Reporter Vector Construction and GRE-GTM3 and GRE-NTM5 Cell Line Establishment}

A lentiviral vector containing the GRE-luciferase expression cassette was constructed using the pGreenFire-mCMVdscGFP-T2A-firefly luciferase-EF1a-puro vector (System Biosciences, Palo Alto, CA) as the backbone. Four repeats of the GRE sequence (5'-GGTACATTTTGTTCT-3') were subcloned upstream of the multiple cloning site of the minimal CMV promoter so that firefly luciferase expression was controlled by glucocorticoid receptor signaling. The vector was verified by sequencing (Genewiz, South Plainfield, NJ). The lentivirus was produced using the Lenti-X packing single shot kit (TakaraBio, Mountain View, CA) and concentrated using ultracentrifugation. 
GTM3 and NTM5 cells were first transduced with the lentiviral glucocorticoid receptor signaling reporter vector and selected using puromycin ( 1 to $16 \mu \mathrm{g} / \mathrm{mL}$ ). The cells that were resistant to puromycin were then transduced with the lenti-CMV-renilla luciferase control vector with the hygromycin-resistant gene (Cignal reporter; Qiagen). The cells were selected with 0.1 to $0.4 \mathrm{mg} / \mathrm{mL}$ hygromycin (Thermoscientific). The double transduced and selected GTM3 and NTM5 cells (named GRE-GTM3 and GRENTM5, respectively) responded to glucocorticoid receptor signaling changes with firefly luciferase expression changes, and these changes could be normalized using renilla luciferase. GRE-GTM3 and GRE-NTM5 used in this study were no more than $\mathrm{p} 7$.

\section{Luciferase Assays}

GTM3 or NTM5 cells (approximately $2 \times 10^{5} / \mathrm{mL}$ ) were seeded into individual wells of 96-well opaque plates (Greiner Bio-One North America Inc., Monroe, NC) for some of the luciferase assays. TCF/LEF (100 ng/well; for canonical Wnt signaling) or GRE (100 ng/well; for glucocorticoid receptor signaling) luciferase reporter vectors (plasmids; Cignal Reporter; Qiagen) were transfected into GTM3 using Attractene transfection reagent at $0.3 \mu \mathrm{L} /$ well (Qiagen GmbH, Hilden, Germany) or Lipofectamine 3000 in Opti-MEM (Invitrogen) using the reverse approach, according to manufacturer's instructions.

For some of the luciferase assays, GRE-GTM3 or GRENTM5 cells were used without reporter vector transfection because they already contain firefly and renilla luciferase cassettes, as described previously. The next day, cells were treated with or without $100 \mathrm{ng} / \mathrm{mL} \mathrm{Wnt} 3 \mathrm{a}, 100 \mathrm{nmol} / \mathrm{L}$ Dex, $0.1 \%$ ethanol, $0.1 \%$ DMSO, and/or GSK3 $\beta$ inhibitors at different concentrations in assay medium (Opti-MEM with $5 \%$ fetal bovine serum) for an additional 24 or 72 hours. At the end of treatment, the Dual-Glow Luciferase Reporter Assay System (Promega, Madison, WI) was used to develop luciferase signal, which was then measured using the Synergy H1 Hybrid Multi-Mode plate reader (BioTek Instruments, Winooski, VT). Firefly luciferase levels were normalized to renilla luciferase levels. All luciferase experiments were performed in replicates.

Some GTM3 cells were first transfected with the glucocorticoid receptor signaling reporter vector (plasmid; Cignal Reporter; Qiagen). The next day, medium was changed to assay medium. On the third day, the cells were transduced with the Ad5-CMV-GFP or Ad5-CMV-Wnt3a+mCherry adenovirus (Vector Biolabs, Malvern, PA) at a multiplicity of infection of 1:50. On the fourth day, the cells were treated with $0.1 \%$ ethanol or $100 \mathrm{nmol} / \mathrm{L}$ Dex for 1 day before the final assay.

The other GTM3 or NTM5 cells were seeded into 96-well opaque plates and transfection was performed using the reverse approach: the cells were added directly to the wells/ plate containing preprepared transfection reagent and DNA/
siRNA mixture, according to manufacturer's instructions. This approach was different from the conventional cell seeding, settlement, and transfection approach, and can save a day during experiments. The DNA/siRNA mixture was prepared with the glucocorticoid receptor signaling reporter vector (plasmid; Cignal Reporter; Qiagen) at $100 \mathrm{ng} / \mathrm{well}$, nontargeting (NT) siRNA or Dkk1 siRNA $(0.1$ or $0.2 \mu \mathrm{L}$ of $50 \mu \mathrm{mol} / \mathrm{L}$ stock siRNA/well), pcDNA3.1 empty vector or pcDNA3.1-Dkk1 plasmid ${ }^{30}$ (100 ng/well), and recombinant human Dkk1 (200 ng/mL; R\&D Systems). For siRNA studies, the next day medium was changed to assay medium containing ethanol or Dex. The cells were treated for 24 or 72 hours before the luciferase assay. For overexpression studies, medium was changed to assay medium the next day. Two days after, the cells were treated with ethanol or Dex for an additional 72 hours before the luciferase assay.

\section{Gene Knockdown in Primary HTM Cells}

Primary HTM cells were seeded in 12-well plates. The next day, HTM cells were transfected with $3 \mu \mathrm{L}$ of $50 \mu \mathrm{mol} / \mathrm{L}$ NT siRNA (Dharmacon, Lafayette, CO), $3 \mu \mathrm{L}$ of $50 \mu \mathrm{mol} / \mathrm{L}$ $\beta$-catenin siRNA (Dharmacon), or $3 \mu \mathrm{L}$ of $50 \mu \mathrm{mol} / \mathrm{L} \mathrm{Dkk1}$ siRNA using $4.5 \mu \mathrm{L}$ HiPerFect transfection reagent (Qiagen) in $500 \mu \mathrm{L}$ Opti-MEM in each well. On the third day, medium was changed to complete medium containing $0.1 \%$ ethanol or $100 \mathrm{nmol} / \mathrm{L}$ Dex. After 48- to 72-hour treatment, proteins were extracted and used for Western immunoblotting for ECM protein analysis.

\section{Immunofluorescence of Primary HTM Cells}

The 2020-001, HTM71FOS, and HTM2018 primary HTM cell strains were plated onto the gelatin-coated number 1.5 or 1.5H glass-bottom 24-well plate (Mattek, Ashland, MA; or CellVis, Mountain View, CA, respectively). After cells reached $100 \%$ cell confluency, cells were incubated in fresh medium containing $0.1 \%$ ethanol, $100 \mathrm{nmol} / \mathrm{L}$ Dex, or Dex + GSK3 $\beta$ inhibitors (BIO, $1 \mu \mathrm{g} / \mathrm{mL}$; SB, $10 \mu \mathrm{g} / \mathrm{mL}$; or CHIR, $5 \mu \mathrm{g} / \mathrm{mL}$ ). Medium was replaced every 3 days throughout the course of the experiment. At 12 to 14 days after treatment, Hoechst $33342(5 \mu \mathrm{g} / \mathrm{mL}$; Thermoscientific) was added directly to medium for nuclei staining. After 10 minutes of incubation with Hoechst 33342, medium was removed, and the cells were washed with room temperature PBS. The cells were fixed using prechilled $100 \%$ methanol for 20 minutes in a $-20^{\circ} \mathrm{C}$ freezer, and then washed three times with PBS. The cells were blocked using Superblock blocking buffer in PBS (Thermofisher Scientific). After blocking, ECM proteins were incubated with primary antibodies (mouse anti-FN-IST9, catalog number ab6328, and mouse anti-FN-BC1, catalog number ab154210 at 1:250; Abcam) at $4^{\circ} \mathrm{C}$ overnight. After three times washing with PBS, the cells were incubated with the secondary goat antimouse Alexa Fluor antibodies (Life Technologies). The cells were imaged using a Zeiss confocal microscope. 
The GC-Induced Mouse Ocular Hypertension Model

Twenty C57BL/6J female mice aged 3 months were purchased from Jackson laboratory (Bar Harbor, ME). Three mice died during the study, and were not included in the analysis $(n=17)$. Mice were housed at the animal facility at University North Texas Health Science Center, and all procedures were approved by Institutional Animal Care and Use Committee. Mice were housed under controlled conditions of temperature $\left(21^{\circ} \mathrm{C}\right.$ to $26^{\circ} \mathrm{C}$ ), humidity ( $40 \%$ to $70 \%$ ), and a 12-hour light/12-hour dark cycle. Food and water were provided ad libitum. Mouse IOP was measured under $2 \%$ isoflurane anesthesia using a Tonolab tonometer (Vantaa, Finland) in a masked manner. ${ }^{20,31}$ Ocular hypertension was induced using a published method. ${ }^{32}$ Briefly, after baseline IOP establishment, both eyes received $200 \mu \mathrm{g}$ of Dex-acetate (Spectrum Chemicals, New Brunswick, NJ) in $20 \mu \mathrm{L}$ of vehicle using a 32-gauge needle and a Hamilton syringe periocularly. Dex-acetate was given for all mice in both eyes once a week throughout the study. After ocular hypertension development (about 2 weeks after initial Dexacetate injection), $3 \times 10^{7}$ plaque-forming units Ad5-CMVGFP were intravitreally injected into the right eye, and $3 \times 10^{7}$ plaque-forming units Ad5-CMV-mouseWn$\mathrm{t} 3 \mathrm{a}+\mathrm{mCherry}$ (co-expression, not a fusion protein) (Vector Biolabs, Malvern, PA) were intravitreally injected into the left eye under anesthesia. Mouse IOP was monitored at about 1:30 PM to achieve consistency throughout the study. At the end of the study, some mouse eyes from euthanized mice were enucleated, fixed with $4 \%$ paraformaldehyde, embedded in paraffin, sectioned, and processed for hematoxylin and eosin staining or immunostaining. For immunostaining, anti-mCherry antibody (Takara) and goat antimouse Alexa-488 antibodies (Thermoscientific) were used. Images were taken using the Nikon $\mathrm{Ti}$ inverted microscope (Nikon, Melville, NY) and Nuance multispectral camera (Perkin Elmer, Waltham, MA).

\section{Statistical Analysis}

Statistical analyses were performed using the Prism GraphPad software version 8.4.3 (San Diego, CA). Oneway analysis of variance and Sidak post-hoc tests were used, and $P<0.05$ was considered statistically significant. For the mouse study, paired $t$-test was used to compare IOP at each time point.

\section{Study Approval}

Human aqueous humor and TM collection: these experiments were conducted according to Declaration of Helsinki principles. Human subjects were provided written informed consent. Aqueous humor collection was approved by the Institutional Review Board of University of North Texas Health Science Center (approval number 2016-094). Trabecular meshwork tissue collection was approved by the

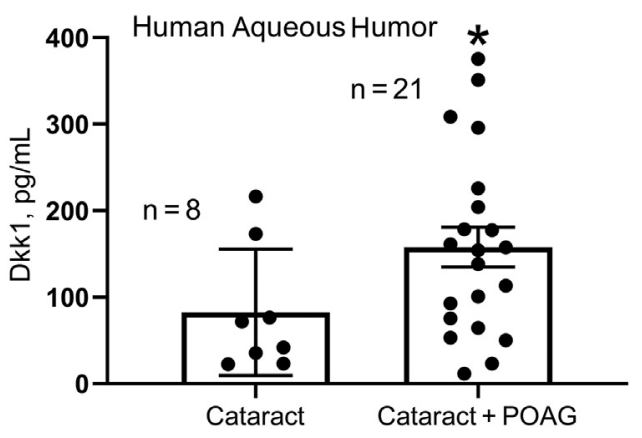

Figure 1 Dkk1 was elevated in the aqueous humor of primary openangle glaucoma (POAG) eyes. Aqueous humor samples were collected from cataract and cataract + POAG patients during surgeries. Dkk1 levels were measured using enzyme-linked immunosorbent assay. Data are given as means \pm SEM. $N=8$ for the cataract group and $N=21$ for the cataract + POAG group. ${ }^{*} P<0.05$ (t-test)

Institutional Review Board of Indiana University-Purdue University at Indianapolis (approval number 1907954322).

Collection of non-glaucomatous TM tissues was exempted by the Institutional Review Board of Indiana University-Purdue University at Indianapolis because no live human subjects were involved.

The animal experiments in this study were approved by the institutional animal care and use committee at University of North Texas Health Science Center (approval number 2015/0002).

\section{Results}

Dkk1 is Significantly Elevated in the Aqueous Humor and TM of POAG Eyes

Dkk1 levels are elevated in bovine Dex responder TM cells compared with nonresponder TM cells as indicated by RNA sequencing. ${ }^{18}$ The results were the motivation behind investigating Dkk1 levels in human eyes. However, because of limited availability of aqueous humor and TM samples from GIG patients (most of the GIG patients without coexistence of POAG do not need surgery), samples from POAG patients were used because about $90 \%$ of POAG patients are responders, ${ }^{4,5,73}$ and POAG and GIG share similarities in pathology. ${ }^{34}$ Although these patient eyes or donor eyes were not treated with GCs, a higher Dkk1 level may indicate the predisposition of those eyes to GC-induced ocular hypertension or GIG.

Aqueous humor collected from cataract or cataract + POAG patients during surgery was used for analyzing Dkk1 using enzyme-linked immunosorbent assay. The result showed elevated Dkk1 levels in the aqueous humor of POAG eyes $(n=21)$ (Figure 1) compared with those of non-POAG eyes, with cataract eyes as a control $(157.79 \pm 22.97$ versus $82.67 \pm 25.81 \mathrm{pg} / \mathrm{mL}$; mean $\pm \mathrm{SEM})(n=8 ; P<0.05)$ (Figure 1).

Furthermore, the expression levels of Dkk1 in the TM tissue of three open-angle glaucoma patients and six 

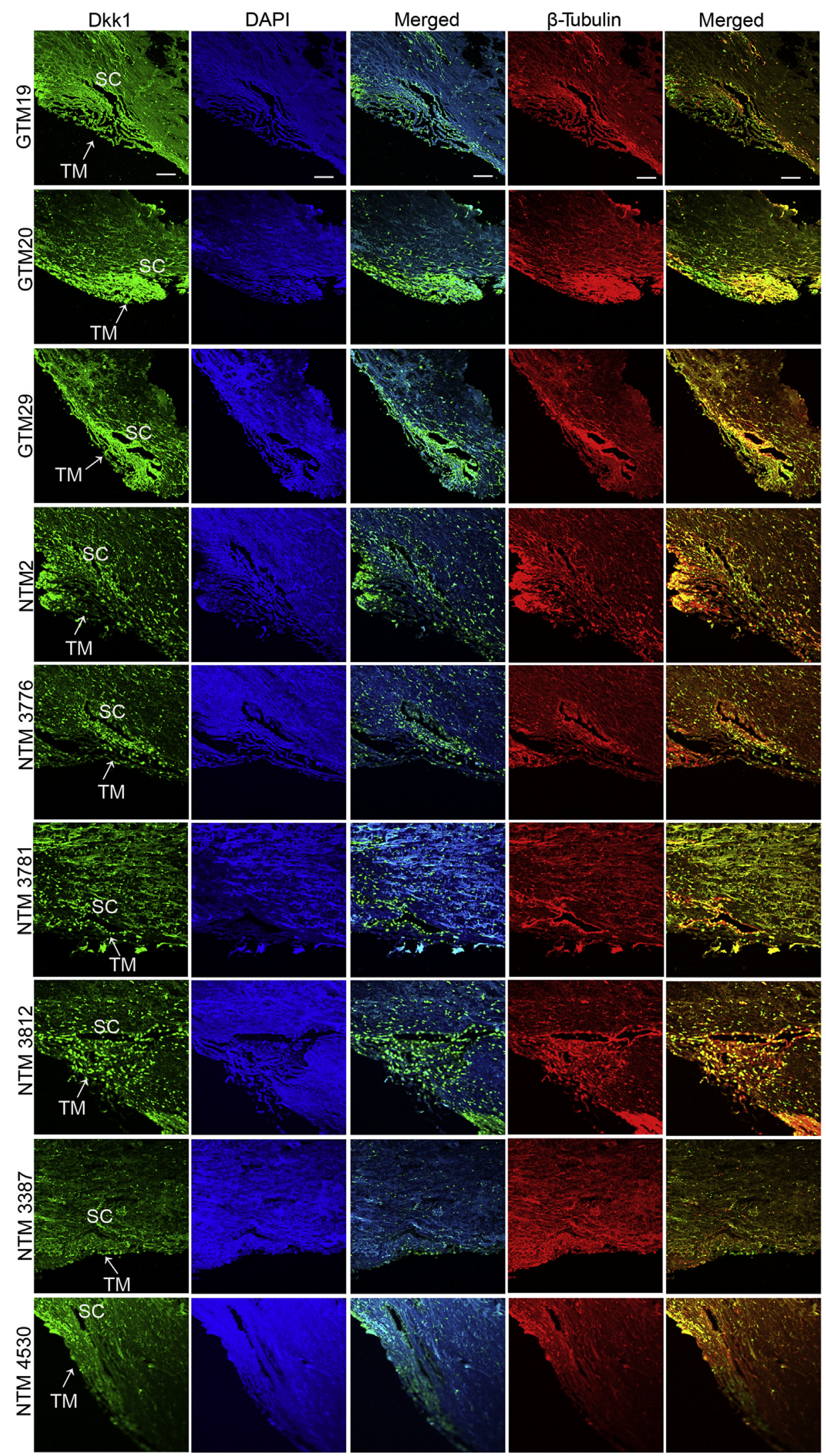

Figure 2 Dkk1 was elevated in the trabecular meshwork (TM) tissue of primary open-angle glaucoma (POAG) eyes. Three glaucomatous TM (GTM) tissues removed during surgeries and six non-glaucomatous TM (NTM) tissues from donor eyes were immunostained with anti-Dkk1 antibody (green) or $\beta$-tubulin (red). $\beta$-Tubulin was used as a quality control because donor eyes were not as fresh as POAG TM tissues (hours versus days). Nuclei were stained with DAPI (blue). Scale bar $=20 \mu \mathrm{m}$. SC, Schlemm canal. 

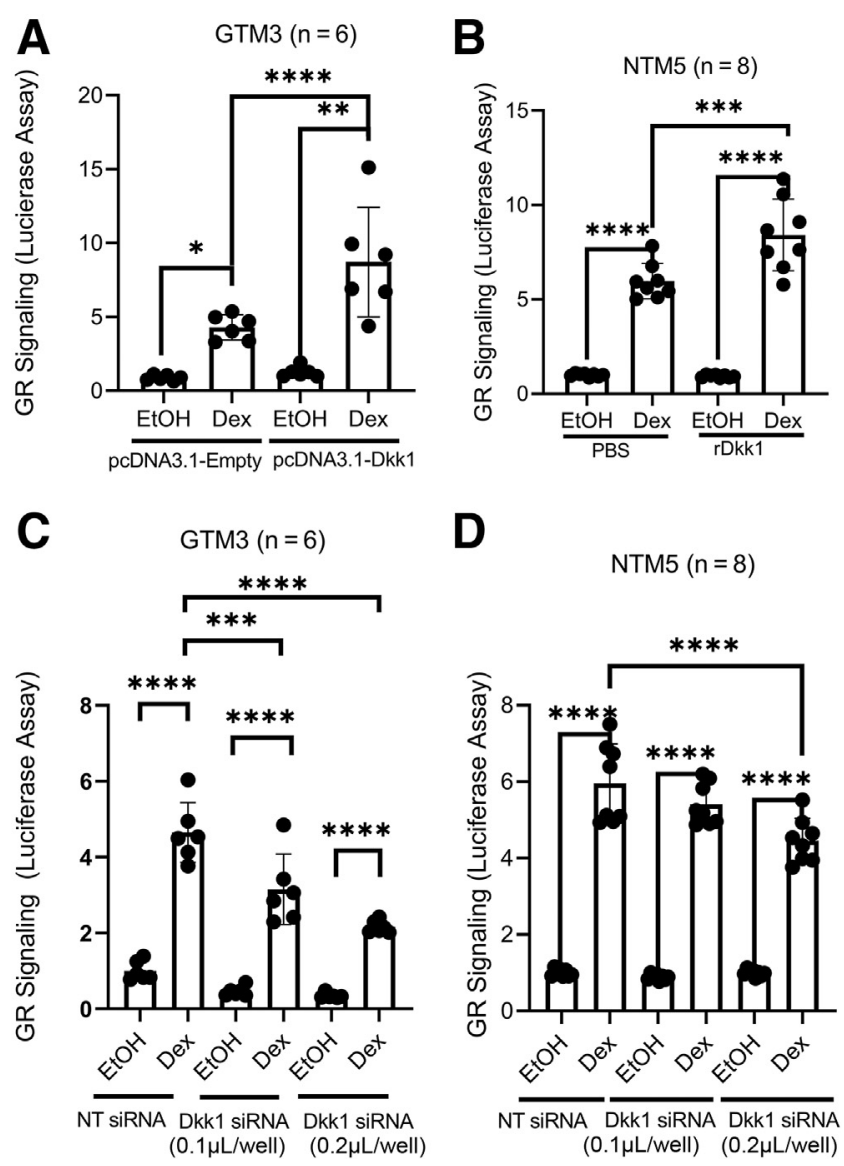

Figure 3 Dkk1 plays a positive role in glucocorticoid receptor (GR) signaling in the human trabecular meshwork (TM). GTM3 cells (A and C) were cotransfected with the glucocorticoid receptor signaling reporter vector together with pcDNA3.1-empty/Dkk1 vector or nontargeting (NT) siRNA/Dkk1 siRNA to overexpress (A) or knock down (C) Dkk1, respectively. Similarly, GRE-NTM5 (B and D), which were stably transduced with glucocorticoid receptor signaling reporter cassettes, were treated/ transfected with phosphate-buffered saline (PBS)/recombinant Dkk1 ( $\mathrm{rDkk1} ; 200 \mathrm{ng} / \mathrm{mL})$ or NT siRNA/Dkk1 siRNA. All cells were treated with $0.1 \%$ ethanol (EtOH) or $100 \mathrm{nmol} / \mathrm{L}$ dexamethasone (Dex) before luciferase assays. Data were analyzed using one-way analysis of variance and Sidak post-hoc tests. Data are given as means \pm SD of GR signaling activity (A-D). $N=6$ (A and C); $N=8$ (B and D). ${ }^{*} P<0.05,{ }^{*} P P<0.01$, $* * * P<0.001$, and $* * * * P<0.0001$.

non-glaucoma donor eyes were compared. Higher expression levels of Dkk1 were observed in the GTM using immunostaining (Figure 2). Because GTM tissues were collected within a few hours after surgical removal while non-glaucomatous TM tissues were collected days postmortem, the difference in tissue freshness could affect the result. Therefore, the tissues were immunostained with the anti- $\beta$-tubulin antibody for quality control. Any potential protein degradation was expected to decrease $\beta$-tubulin as well. Immunostaining showed that $\beta$-tubulin fluorescent intensity was similar in both groups, confirming the elevation of Dkk1 in the GTM. To quantitate Dkk1 expression levels, the fluorescent intensity of Dkk1 and $\beta$-tubulin was measured and normalized using the images indicated in
Figure 2. Densitometry results confirmed an elevation of Dkk1 in the GTM compared with that in the NTM $(P<0.05)$ (Supplemental Figure S1).

\section{Dkk1 Functions as a Positive Regulator of the Glucocorticoid Receptor Signaling Pathway}

To confirm the role of Dkk1 in regulating glucocorticoid receptor signaling, luciferase assays designed for glucocorticoid receptor signaling activities were used and the level of Dkk1 was manipulated in two transformed TM cell lines: GTM3 and NTM5, which originated from glaucomatous and non-glaucomatous donors, respectively. ${ }^{23}$ Transformed cells were used because it is difficult to transfect primary HTM cells with expression plasmids such as luciferase reporter vectors (plasmids), whereas transfection is easily achievable in transformed TM cells. Although transfection with siRNA has been successful, including in this study, transfection with expression plasmids has not been reported in primary HTM cells. Because there are no commercial lentivirus-based glucocorticoid receptor signaling reporter vectors, a vector was constructed and tested in primary HTM cells. However, the efficiency of the vector was not suitable for this study (data not shown). Instead, the vector together with another commercial vector were used to construct a stably transduced glucocorticoid receptor signaling reporter line (GRE-NTM5; see Materials and Methods for details).

To overexpress Dkk1, GTM3 cells were cotransfected with luciferase reporter vectors (plasmids) together with pcDNA3.1-empty or pcDNA3.1-Dkk1 vector. After 3 days, the cells were treated with $0.1 \%$ ethanol or $100 \mathrm{nmol} / \mathrm{L}$ Dex for one additional day before performing the luciferase assay. GRE-NTM5 cells were directly treated with/without $200 \mathrm{ng} / \mathrm{mL}$ recombinant Dkk1 for 3 days, followed by ethanol or Dex treatment for 1 day. The results showed that Dex induced glucocorticoid receptor signaling in GTM3 and GRE-NTM5 cells (positive controls) (Figure 3). More importantly, overexpression or recombinant Dkk1 enhanced glucocorticoid receptor signaling in GTM3 cells by approximately $103 \%$ (Columns 2 vs. $4 ; n=6 ; P<0.0001$ ) (Figure $3 \mathrm{~A}$ ) and in GRE-NTM5 cells by approximately $41 \%$ (Columns 2 vs. $4 ; n=8 ; P<0.001$ ) (Figure 3B), respectively. In contrast, the baseline glucocorticoid receptor signaling activity was not significantly affected (Columns 1 vs. $3 ; P>0.05$ ) (Figure $3, \mathrm{~A}$ and $\mathrm{B}$ ).

To knock down Dkk1, GTM3 cells were cotransfected with the glucocorticoid receptor signaling reporter vector (plasmid) and NT siRNA/Dkk1 siRNA. GRE-NTM5 cells were transfected with NT siRNA/Dkk1 siRNA. The next day, the cells were treated with $0.1 \%$ ethanol and/or 100 $\mathrm{nmol} / \mathrm{L}$ Dex for an additional day before assay. Luciferase assays showed that although Dex induced glucocorticoid receptor signaling in all siRNA treatment groups, Dkk1 siRNA partially and dose-dependently inhibited glucocorticoid receptor signaling both in GTM3 (32\% reduction at 

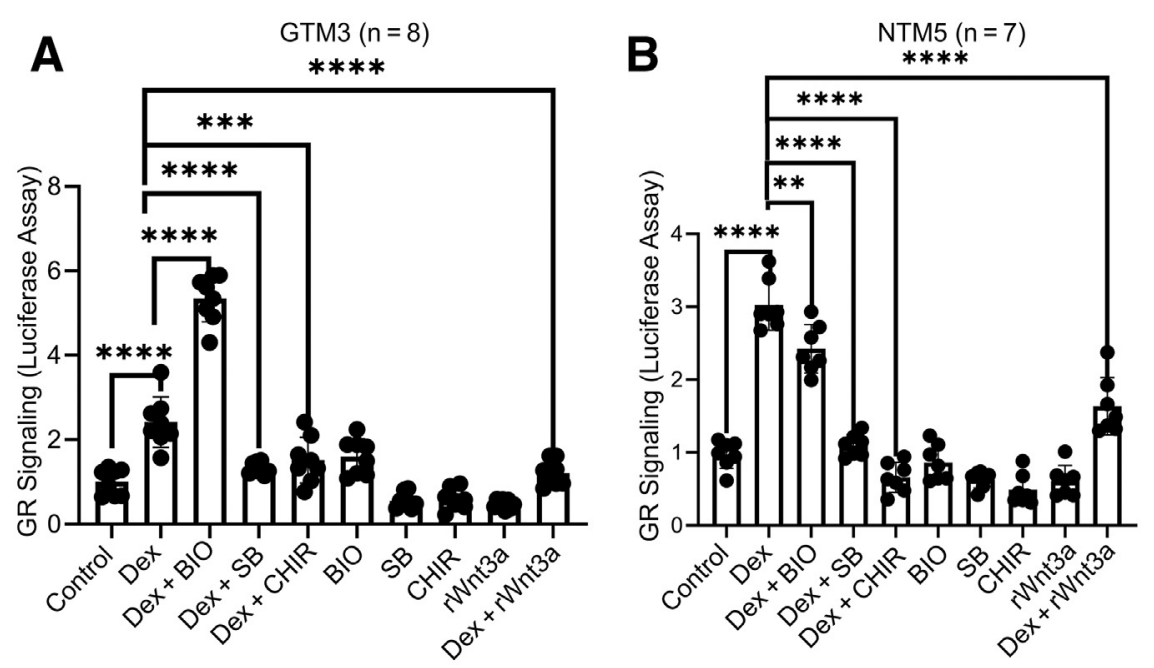

Figure 4 Wnt signaling inhibits glucocorticoid receptor (GR) signaling in the human trabecular meshwork (TM). GRE-GTM3 (A) and GRE-NTM5 (B) cells were treated with or without indicated glycogen synthase kinase $3 \beta$ inhibitors $[1 \mu \mathrm{mol} / \mathrm{L}$ 6-bromoindirubin-3'-oxime (BI0), $10 \mu \mathrm{mol} / \mathrm{L} \mathrm{SB}$ 216763 (SB), or $5 \mu \mathrm{mol} / \mathrm{L}$ CHIR99021 (CHIR)] together with $0.1 \%$ ethanol [vehicle for dexamethasone (Dex)] and/or $100 \mathrm{nmol} / \mathrm{L}$ Dex before luciferase assays. Data were analyzed using one-way analysis of variance and Sidak post-hoc tests. Data are given as means \pm SD of GR signaling activity (A and $\mathbf{B}) . N=8$ (A); $N=7$ (B). ${ }^{* * P}<0.01,{ }^{* *} P<0.001$, and $* * * * P<0.0001$. rWnt3a, recombinant Wnt3a.

$0.1 \mu \mathrm{L}$ versus $54 \%$ reduction at $0.2 \mu \mathrm{L}$; columns 2 vs. 4 compared to columns 2 vs. $6 ; n=6 ; P<0.001)$ (Figure 3C) and GRE-NTM5 cells (9\% reduction at $0.1 \mu \mathrm{L}$ versus $25 \%$ reduction at $0.2 \mu \mathrm{L}$; columns 2 vs. 4 compared to columns 2 vs. $6 ; n=6 ; P<0.001$ ) (Figure 3D).

\section{Activation of Canonical Wnt Signaling Inhibits Glucocorticoid Receptor Signaling}

To study whether activation of Wnt signaling alters glucocorticoid receptor signaling, GRE-GTM3 cells (constructed similar to GRE-NTM5) and GRE-NTM5 cells were treated with or without $100 \mathrm{nmol} / \mathrm{L}$ Dex with or without $100 \mathrm{ng} / \mathrm{mL}$ recombinant Wnt3a or GSK3 $\beta$ inhibitors for 1 day before assay. The three GSK $3 \beta$ inhibitors BIO, SB, and CHIR are known to activate the canonical Wnt signaling by inhibition of the $\beta$-catenin degradation complex because GSK3 $\beta$ is one of the components of the complex. ${ }^{29}$ The indicated concentrations were selected on the basis of the results of dose-response study (Supplemental Figure S2.)

Luciferase assays showed that Wnt3a inhibited Dex-induced glucocorticoid receptor signaling in GREGTM3 cells by approximately 50\% ( $n=8$; $P<0.001)$ (Figure 4A) and GRE-NTM5 cells by approximately $46 \%$ ( $n=7 ; P<0.001$ ) (Figure 4B). Similar to Wnt3a, GSK3 $\beta$ inhibitors inhibited glucocorticoid receptor signaling (Figure 4).

\section{Glucocorticoid Receptor Signaling Inhibits Canonical Wnt Signaling in TM Cells}

Because the results described previously showed that Wnt signaling inhibited glucocorticoid receptor signaling, further studies were conducted to determine how glucocorticoid receptor signaling affects Wnt signaling in the TM. GTM3 and NTM5 cells were transfected with the TCF/LEF luciferase reporter vectors. After 24 hours, transfected cells were treated with $0.1 \%$ ethanol or $100 \mathrm{nmol} / \mathrm{L}$ Dex with or without $100 \mathrm{ng} / \mathrm{mL}$ Wnt3a for additional 3 days. Luciferase assays showed that Dex significantly inhibited Wnt signaling in the absence or presence of Wnt3a in GTM3 cells by approximately $65 \%(n=8 ; P<0.01$ or $P<0.0001$ ) (Figure 5A) and in NTM5 cells by approximately 76\% ( $n=8 ; P<0.001$ or $P<0.0001)$ (Figure $5 \mathrm{~B})$. As a positive control, Wnt3a was used to activate Wnt signaling in both GTM3 and NTM5 cells $(P<0.0001)$ (Figure 5).

\section{Activation of Canonical Wnt Signaling Inhibits Dex-Induced ECM Proteins in Primary HTM Cells}

It has been well-documented that GCs induce ECM proteins in the TM, which contributes to elevated outflow resistance and IOP. ${ }^{3}$ Therefore, primary HTM cell-based assays were conducted to determine whether activation of Wnt signaling using GSK3 $\beta$ inhibitors is able to inhibit GC-induced ECM in primary HTM cells.

Three primary HTM cell strains (HTM75OS, HTM71FOS, and 2019-017) were used. These primary TM cells were characterized using well-established criteria for cultured TM cells. $^{27}$ The cells were treated with $0.1 \%$ ethanol or $100 \mathrm{nmol} / \mathrm{L}$ Dex together with or without GSK3 $\beta$ inhibitors or DMSO (vehicle) for 72 hours. The level of FN as well as collagen-I in conditioned medium and whole cell lysate was studied using Western immunoblotting. The results showed that all GSK3 $\beta$ inhibitors inhibited FN and collagen-I at baseline and Dex-induced levels in both conditioned medium and whole cell lysate (Figure 6, A-C).

$\mathrm{FN}$ has cellular FN or plasma FN isoforms. Cellular FN is insoluble and a major component of ECM, whereas plasma FN is soluble. Also, cellular FN has multiple alternatively spliced subisoforms. ${ }^{35}$ Studies show that the extra domainA (EDA)-FN isoform is elevated in the glaucomatous TM, ${ }^{36}$ and extra domain-B (EDB)-FN may also play a role. 

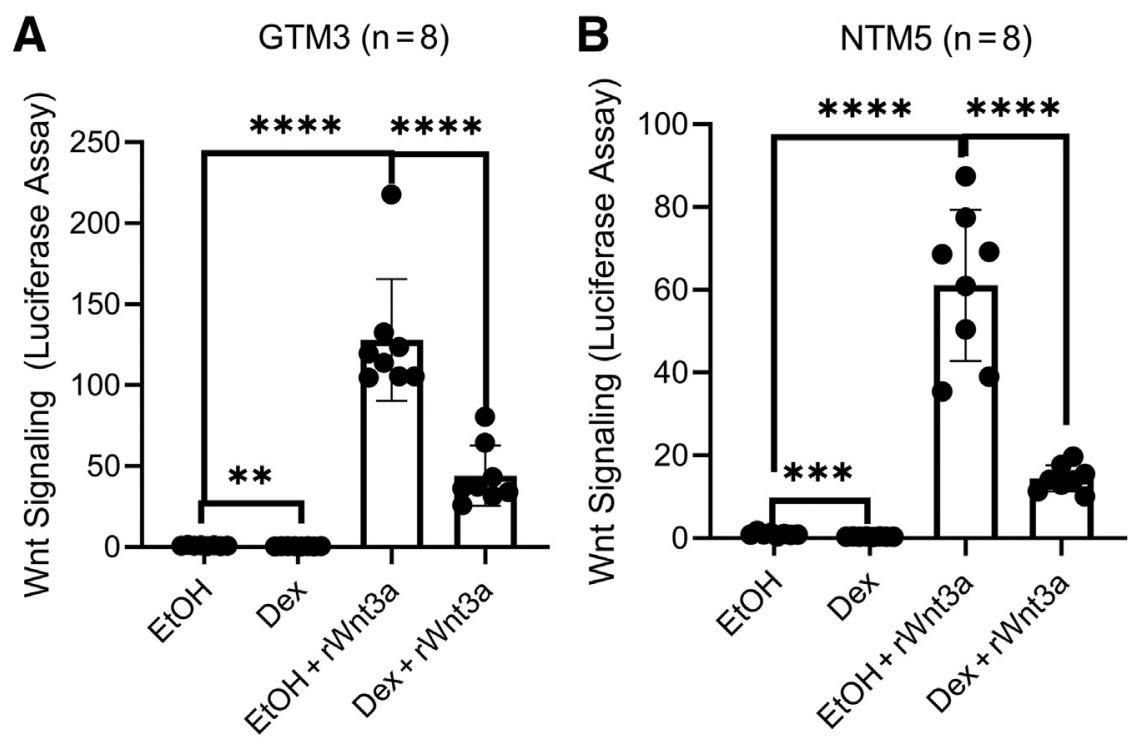

Figure 5 Glucocorticoid receptor signaling inhibits Wnt signaling in the human trabecular meshwork (TM). GTM3 (A) and NTM5 (B) cells were transfected with the Wnt signaling reporter vector and treated with $0.1 \%$ ethanol (EtOH) or 100 $\mathrm{nmol} / \mathrm{L}$ dexamethasone (Dex) with or without $100 \mathrm{ng} / \mathrm{mL}$ Wnt3a for 72 hours before luciferase assays. Data were analyzed using one-way analysis of variance and Sidak post-hoc tests. Data are given as means $\pm S D$ of canonical Wnt signaling activity (A and B). $N=8$ (A and $\mathbf{B}) .{ }^{* *} P<0.01$, $* * * P<0.001$, and $* * * * P<0.0001$. rWnt3a, recombinant Wnt3a.
Therefore, to determine the two isoforms of cellular FN, immunocytofluorescence was used to determine their expression. Three primary HTM (2020-001, HTM71FOS, and HTM2180) cell strains were treated with $0.1 \%$ ethanol, $0.1 \% \mathrm{DMSO}$ as a control, or $100 \mathrm{nmol} / \mathrm{L}$ Dex together with GSK3 $\beta$ inhibitors (BIO, SB, or CHIR in DMSO vehicle) for 12 to 14 days. Immunostaining showed that Dex induced the expression of EDA-FN and EDB-FN, and this induction was inhibited by GSK3 $\beta$ inhibitors (Figure 6, D-F).

\section{Dkk1 Knockdown Inhibits ECM in HTM Cells}

Because direct activation of canonical Wnt signaling using GSK3 $\beta$ inhibitors decreased ECM in primary HTM cells, primary HTM cell-based assays were used to determine whether indirect activation of endogenous canonical Wnt signaling by knocking down Dkk1, the Wnt inhibitor, would produce the same effects as using GSK3 $\beta$ inhibitors.

Primary HTM cells (2180, HTM71FOS, and 2023) were transfected with NT siRNA or Dkk1 siRNA, followed by treatment with $0.1 \%$ ethanol or $100 \mathrm{nmol} / \mathrm{L}$ Dex for additional 3 days. Whole cell lysates and conditioned medium were collected and analyzed for FN and collagen-I using Western blotting. As a quality control, Dkk1 levels were greatly reduced in both protein fractions. Western immunoblotting showed that knocking down of Dkk1 inhibited both FN and collagen-I protein expression in conditioned medium as well as whole cell lysates at baseline and Dexinduced levels (Figure 7).

\section{$\beta$-Catenin Knockdown Increases ECM in HTM Cells}

$\beta$-Catenin is the key component of the canonical Wnt signaling pathway. Because direct and indirect activation of canonical Wnt signaling inhibited ECM in the TM, as described previously, primary HTM cell-based assays were used to determine whether inhibition of canonical Wnt signaling by knocking down $\beta$-catenin increases ECM.

Primary HTM cells (2180, HTM71FOS, and 2019-017) were transfected with NT siRNA or $\beta$-catenin siRNA. The next day, the cells were treated with $0.1 \%$ ethanol or 100 $\mathrm{nmol} / \mathrm{L}$ Dex for an additional 2 days. Whole cell lysates and conditioned medium were collected for Western immunoblotting (Figure 8). The result showed that $\beta$-catenin was reduced in cells transfected with $\beta$-catenin siRNA compared with those transfected with NT siRNA. In all HTM strains, $\beta$-catenin knockdown consistently increased FN and collagen-I at baseline and Dex-induced levels in conditioned medium. Also, $\beta$-catenin knockdown consistently increased $\mathrm{FN}$ at baseline and Dex-induced levels in whole cell lysate. In contrast, the induction of collagen-I in whole cell lysate was not as significant as that in conditioned medium, probably due to rapid protein secretion.

These data suggest that inhibition of the canonical Wnt signaling increases ECM in the TM.

\section{Wnt Signaling Decreases Dex-Induced Ocular Hypertension in Mouse Eyes}

Mouse eyes were used to determine whether Wnt signaling is able to inhibit Dex-induced ocular hypertension. Ocular hypertension was induced using Dex and overexpressing Wnt3a using Ad5 adenovirus in the mouse TM.

First, as a quality control, luciferase assays were used to test whether the Ad5-CMV-Wnt3a viral vector was able to inhibit glucocorticoid receptor signaling in GTM3 cells, like using recombinant Wnt3a or GSK3 $\beta$ inhibitors (Figure 9A). The GRE-GTM3 cells were transduced with Ad5-CMV-GFP or Ad5-CMV-Wnt3a+mCherry (co-expression, not a fusion protein) viral vectors. After 24 hours, the cells were treated 
A

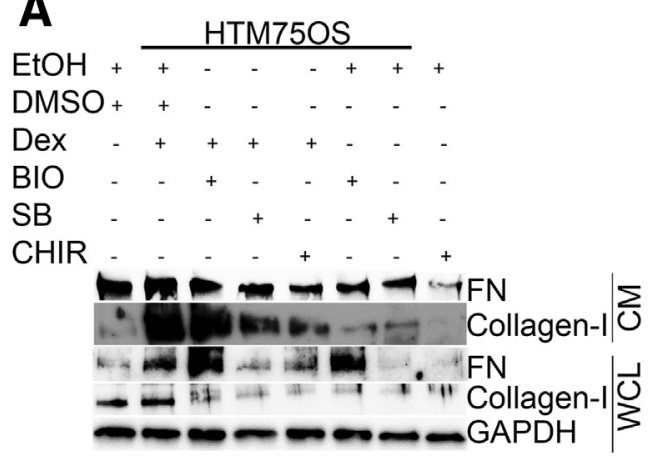

C
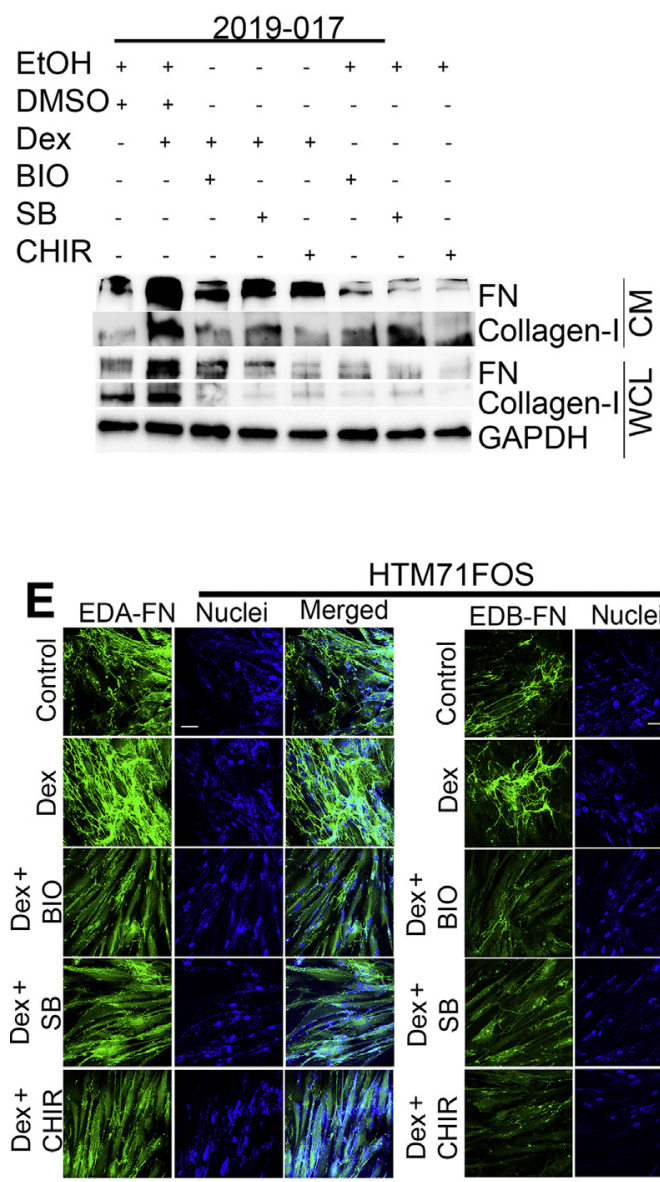

HTM71FOS

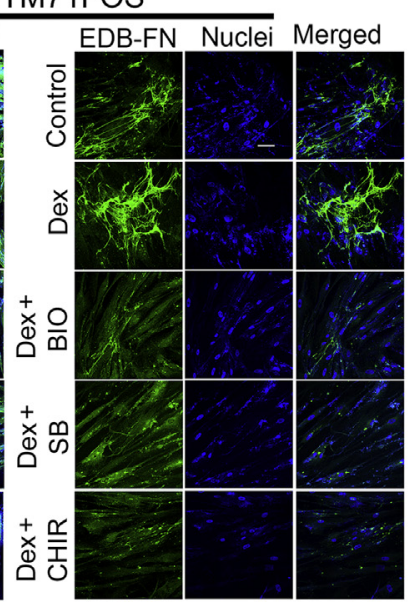

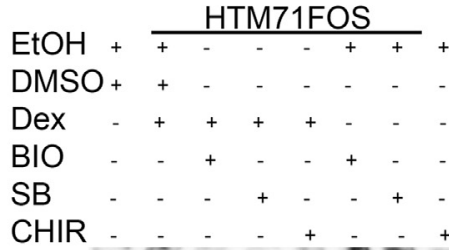

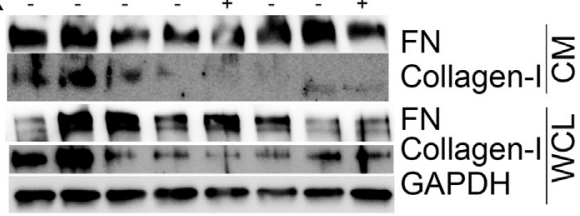

D

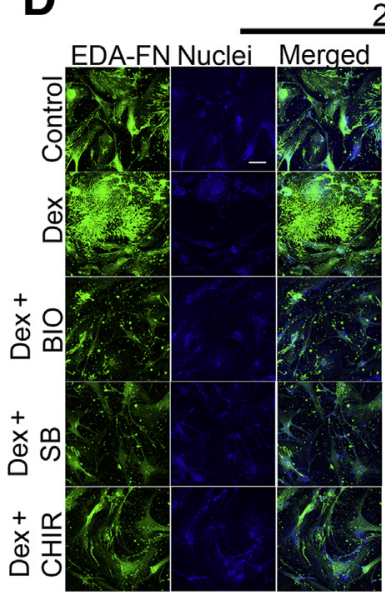

2020-001

Figure 6 Activation of Wht signaling inhibits dexamethasone (Dex)-induced extracellular matrix in primary human trabecular meshwork (HTM) cells. HTM750S (A), HTM71FOS (B), and 2019-017 (C) primary HTM cells were treated with 0.1\% ethanol (EtOH; vehicle), dimethyl sulfoxide (DMSO; vehicle), $100 \mathrm{nmol} / \mathrm{L}$ Dex, $1 \mu \mathrm{mol} / \mathrm{L}$ 6-bromoindirubin-3'-oxime (BI0), $10 \mu \mathrm{mol} / \mathrm{L} \mathrm{SB}-216763$ (SB), and/or $5 \mu \mathrm{mol} / \mathrm{L}$ CHIR99021 (CHIR) for 72 hours. Fibronectin (FN) and collagen-I from conditioned medium (CM) and whole cell lysate (WCL) were used for Western immunoblotting. Glyceraldehyde-3-phosphate dehydrogenase (GAPDH) served as a loading control for WCL. The 2020-001 (D), HTM71FOS (E), and HTM2180 (F) primary HTM cells were treated with 0.1\% Et0H (vehicle), DMS0 (vehicle), 100 nmol/L Dex, and Dex + glycogen synthase kinase $3 \beta$ inhibitors $(1 \mu \mathrm{mol} / \mathrm{L} \mathrm{BI0}, 10 \mu \mathrm{mol} / \mathrm{L} \mathrm{SB}$, and/or $5 \mu \mathrm{mol} / \mathrm{L} \mathrm{CHIR)} \mathrm{for} 12$ to 14 days, and were immunostained with anti-EDA-FN or EDB-FN antibodies (green). Nuclei were stained using Hoechst-33342 and/or DAPI (blue). Scale bar $=20 \mu \mathrm{m}$ (D-F).

with $0.1 \%$ ethanol or $100 \mathrm{nmol} / \mathrm{L}$ Dex for 1 day before luciferase assay. The results showed that Ad5-CMV-Wnt3a transduction inhibited Dex-induced glucocorticoid receptor signaling by approximately $44 \%(n=8 ; P<0.0001)$ (Figure 9A).
After viral vector validation, the Dex-induced ocular hypertension mouse model reported by Patel et $\mathrm{al}^{32}$ was used for this study. The mice were injected with $200 \mu \mathrm{g}$ Dex-acetate periocularly in both eyes once a week throughout the study to induce and maintain ocular 

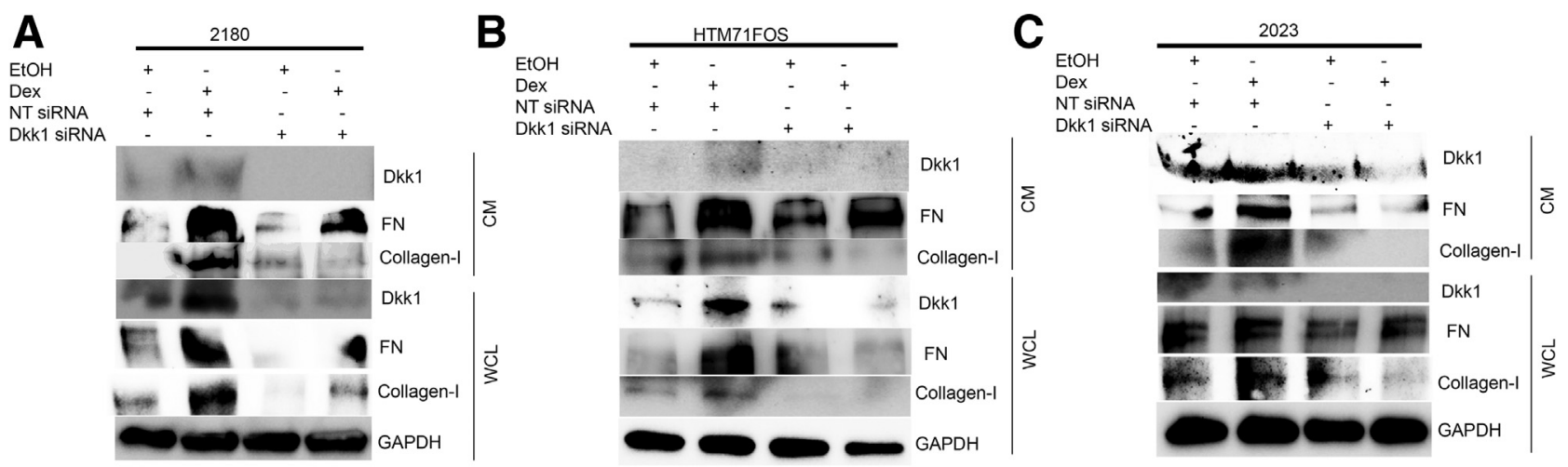

Figure 7 Dkk1 knockdown inhibits extracellular matrix in primary human trabecular meshwork (HTM) cells. HTM 2180 (A), HTM71F0S (B), and HTM2023 (C) cells were transfected with nontargeting (NT) siRNA/Dkk1 siRNA. The cells were treated with $0.1 \%$ ethanol (EtOH) or $100 \mathrm{nmol} / \mathrm{L}$ dexamethasone (Dex) for 3 days, and conditioned medium (CM) and whole cell lysate (WCL) were harvested for Western immunoblotting. Glyceraldehyde-3-phosphate dehydrogenase (GAPDH) served as a loading control for WCL. FN, fibronectin.

hypertension. After ocular hypertension induction, the mice were intravitreally injected with Ad5-CMV-Wnt3a+mCherry or Ad5-CMV-GFP into one of the eyes to induce Wnt signaling or as a control, respectively. Ad5 viruses were given only once. Intraocular pressure data showed that Wnt3a alleviated Dex-induced ocular hypertension compared with the fellow control eyes starting from day 23 after viral injection $(n=17$; paired $t$-test; all $P$ values were $<0.01$ or $<0.05$ after day 20) (Figure 9B). Detailed IOP data were included in Supplemental Table S3.

To determine the morphology and expression of Wnt3a, hematoxylin and eosin staining as well as immunostaining using the anti-mCherry antibody were performed. These studies showed that the anterior chamber appeared normal and Wnt3a was expressed in the TM (Figure 9, C and D).

Overall, the mouse data shows that activation of Wnt signaling inhibited Dex-induced ocular hypertension.

\section{Discussion}

Glucocorticoids are effective in treating ocular inflammation and other diseases, but their adverse effects, especially ocular hypertension and GIG ${ }^{4-6}$ frequently force patients to pause or stop the treatment. In some cases, ocular hypertension persists after GC withdrawal. ${ }^{37}$ Many studies have investigated safe GCs that do not induce ocular hypertension. The results of the current study suggest a potential approach of suppressing glucocorticoid receptor signaling, GC-induced ECM changes, and ocular hypertension by activation of canonical Wnt signaling in the TM.

In light of our published RNA sequencing data, ${ }^{18}$ in this study, the canonical Wnt signaling inhibitor Dkk1 levels were investigated in glaucomatous eyes. This study showed that the level of Dkk1 in the aqueous humor of POAG eyes was almost twice as high as that in non-POAG eyes. An elevation of Dkk1 in the POAG tissue was also observed. To the best of our knowledge, this is the first study that has reported elevated Dkk1 in glaucomatous eyes.

Although elevated Dkk1 was found in the glaucomatous aqueous humor, the exact source(s) of Dkk1 remains unclear. Theoretically, any tissue that has direct contact with the aqueous humor may contribute to Dkk1 elevation, including the ciliary body, iris, lens, cornea endothelium, and TM. The current data showed that at least the TM is a contributor of the aqueous humor Dkk1 because the GTM

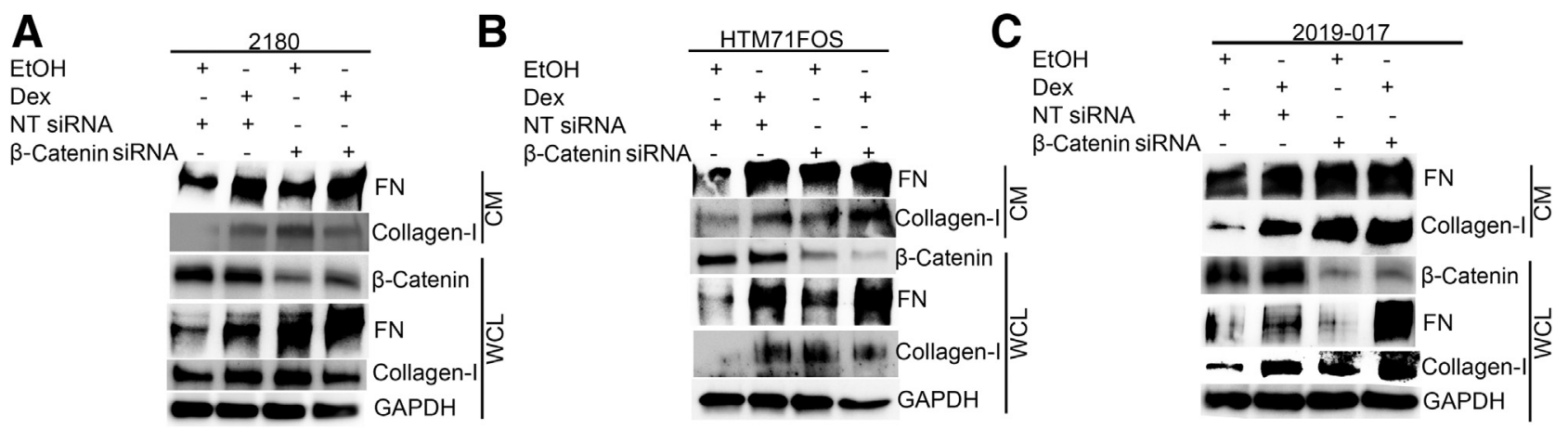

Figure 8 Inhibition of canonical Wnt signaling increases extracellular matrix in primary human trabecular meshwork (HTM) cells. HTM 2180 (A), HTM71F0S (B), and 2019-017 (C) HTM cells were transfected with nontargeting (NT) siRNA/ $\beta$-catenin siRNA. The cells were treated with $0.1 \%$ ethanol (EtOH) or $100 \mathrm{nmol} / \mathrm{L}$ dexamethasone (Dex) for 2 days, and conditioned medium (CM) as well as whole cell lysate (WCL) were harvested for Western immunoblotting. Glyceraldehyde-3-phosphate dehydrogenase (GAPDH) served as a loading control for WCL. FN, fibronectin. 

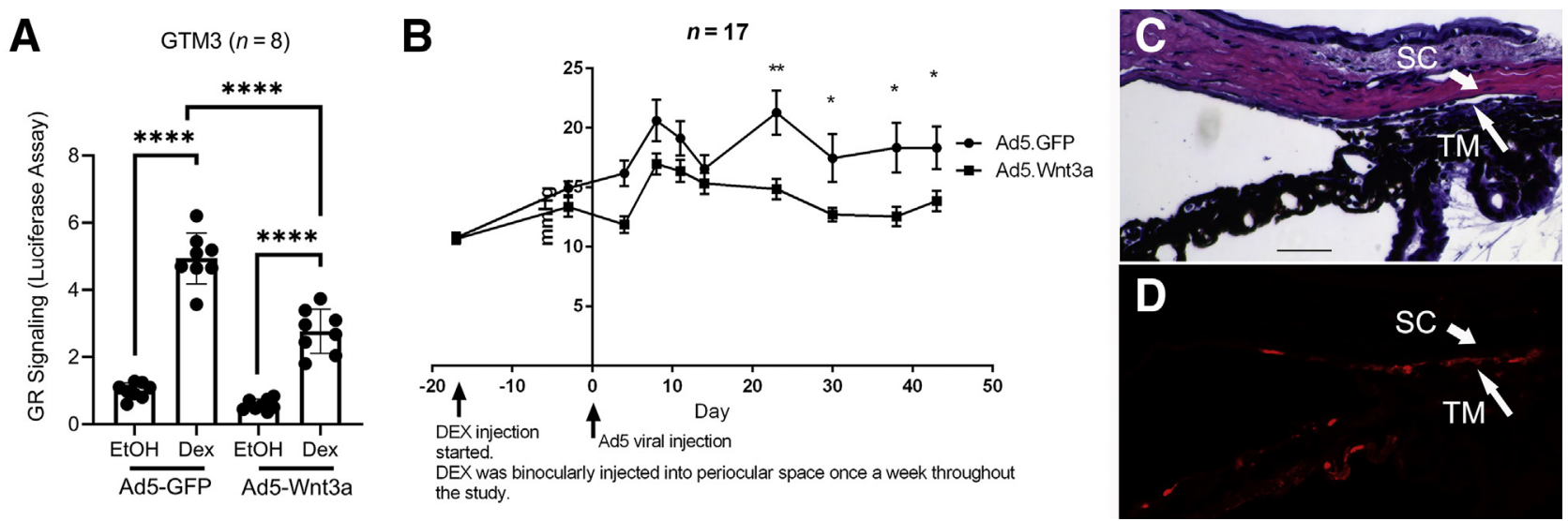

Figure 9 Wnt3a reduces ocular hypertension in dexamethasone (Dex)-treated mice. A: GTM3 cells were transfected with the glucocorticoid receptor (GR) signaling reporter vector and transduced with the Ad5-CMV-GFP or Ad5-CMV-Wnt3a+mCherry before luciferase assays. Data were analyzed using one-way analysis of variance and Sidak post-hoc tests. B: Three-month-old female C57BL/6J mice received binocular periocular Dex-acetate (Dex-Ac) injection once a week throughout the study (arrow on the left) after baseline intraocular pressure (IOP) establishment. After ocular hypertension development, Ad5CMV-GFP was injected intravitreally into one eye and Ad5-CMV-Wnt3a+mCherry was injected into the fellow eye (arrow on the right). Mouse IOP was measured under isoflurane anesthesia about once a week throughout the study in a masked manner. Paired $t$-test was used to compare IOP at each time point. C: Hematoxylin and eosin (H\&E) staining of a mouse eye section transduced with Ad5-Wnt3a-mCherry. D: Immunostaining of a section adjacent to $\mathbf{C}$ using the anti-mCherry antibody (red; pseudocolor). Data are given as means \pm SD of GR signaling activity (A) or means \pm SEM of IOP (B). $N=8(\mathbf{A}) ; N=17$ (B). ${ }^{*} P<0.05 ;{ }^{* *} P<0.01$, and ${ }^{* * * *} P<0.0001$. Scale bar $=40 \mu \mathrm{m}$ (C).

tissues showed more Dkk1. This localized Dkk1 elevation may be due to increased Dkk1 production in the GTM; or the GTM cells/tissues retain more Dkk1 when the aqueous humor passes through the TM; or both. This localized Dkk1 elevation may help to explain why the TM, not other ocular tissues, is primarily affected in glaucomatous eyes. Further research is needed to determine the role of non-TM tissues in Dkk1 elevation in the glaucomatous aqueous humor.

Different from sFRP1, which sequesters Wnt proteins and whose elevation in GTM, ${ }^{21,22}$ Dkk1 functions by inhibiting the LRP5/6 coreceptor and therefore is relatively specific in the inhibition of canonical Wnt signaling. Combining published data that Dkk1 is differentially regulated in bovine responder $\mathrm{TM}^{18}$ with current results that Dkk1 positively regulates glucocorticoid signaling, it is reasonable to believe that Dkk1 as well as canonical Wnt signaling are key players of GCinduced ocular hypertension.

Using aqueous humor and TM tissues for glaucoma research is an important approach to assess in vivo clinical conditions. However, this approach does have limitations. For example, aqueous humor contamination by blood, tears, and even excessive aqueous humor aspiration (that may damage blood-aqueous barrier) may affect the results. Also, it is impossible to obtain fresh TM tissues from non-glaucoma subjects, where postmortem TM tissues may have changes in protein contents. In addition, patients' medication history may affect the proteins of interest. In this study, aqueous humor samples with potential contaminations and excessive volumes were excluded, and a cytoskeletal protein was used as an internal control to validate TM tissues. Because almost all glaucoma patients who undergo glaucoma surgery only after ocular hypotensive medicines are no longer effective in IOP control, it is difficult to obtain either samples without being exposed to these medicines. Therefore, any significant findings from clinical samples are likely to be validated using glaucoma research models.

In this study, HTM cell models and a published mouse Dex model were used to validate the role of Dkk1 and canonical Wnt signaling in GC-induced ocular hypertension. The results from both modeling systems suggested that canonical signaling inhibits glucocorticoid receptor signaling and vice versa.

The determination of cell signaling activities in this study relied heavily on transformed TM cells (GTM3 and NTM5) because of previously described difficulty in introducing multiple expression vectors into primary HTM cells. Because transformed TM cells behave differently from primary HTM cells, the signaling changes observed in transformed TM cells might be different from those observed in primary HTM cells.

Another concern of using transformed TM cells is the difference in siRNA efficiency. In primary HTM cells, a high efficiency of gene knockdown, especially for Dkk1, was observed, and this knockdown greatly affected the ECM (Figure 7). In contrast, Dkk1 knockdown in transformed TM cells only inhibited about $50 \%$ glucocorticoid receptor signaling (Figure 3). This discrepancy could be due to rapid cell proliferation (rapid proliferation of transformed cells could dilute the effect of Dkk1 siRNA and make it less efficient); and/or the nonlinearity of the biological system. For example, $75 \%$ knockdown of Dkk1 may produce 50\% signaling reduction, whereas $80 \%$ knockdown may produce $75 \%$ signaling reduction. Therefore, with the development of new, effective viral expression and reporter vectors for primary HTM cells in the future, similar assays will need to be conducted to validate the findings in transformed TM cells. 
The cross talk between Wnt and glucocorticoid receptor signaling has been reported in non-TM cells. In the bone, studies showed that activation of Wnt signaling by blocking Sclerostin (SOST) inhibits glucocorticoid receptor signaling and GC-induced osteoporosis, ${ }^{38,39}$ whereas GCs inhibit Wnt signaling by up-regulating Wnt inhibitors, including Dkk1, SOST, or Wnt inhibitory factor 1 (WIF-1). ${ }^{40-44}$ Those results are consistent with the findings in the HTM in this study.

In contrast, the studies of such cross talk in the TM are limited. Kwon et $\mathrm{al}^{45}$ suggested that myocilin, a glucocorticoid receptor signaling regulated gene (Dex-inducible myocilin expression is the generally accepted criteria for TM characterization $^{27,46}$ ), modulates Wnt signaling, but the study was performed in HEK293 cells, not in TM cells. Yuan et $\mathrm{al}^{47}$ reported that Dex induces Wnt5a but suppresses Wnt2 and Wnt 3 , and suggested that Wnt5a induces cross-linked actin network formation via the noncanonical Wnt pathway. However, the TM cell strain used in the study is less likely to be an authentic TM strain, as shown by several TM research groups. ${ }^{27}$

Ahadome et $\mathrm{al}^{48}$ reported that a small-molecule Wnt inhibitor, 3235-0367, abrogates Dex-induced collagen expression at the mRNA level, whereas a Wnt activator, BML-284 (mechanism of Wnt activation unclear), enhanced collagen expression at basal levels (cotreatment using BML-284 and Dex was not reported). They also found that Dex slightly induced axin2 mRNA expression by about $50 \%$ to $100 \%$ after 10-day treatment, indicating that Dex enhanced canonical Wnt signaling. ${ }^{48}$ The results from that study are different from ours. The difference could be due to:

1) Small-molecule compound specificity.

These compounds are more selective at certain concentrations. Therefore, in this study, three well-characterized GSK3 $\beta$ inhibitors ${ }^{29}$ were tested, and their optimal concentrations were determined in the TM. All three compounds showed consistent ECM reduction.

2) Treatment duration and Wnt activation/ECM markers.

In this study, the TM cells were treated for 1 to 14 days with Dex in two transformed TM lines and five primary TM cell strains in different assays (luciferase assay, ECM studies, knockout and overexpression, plus the in vivo mouse model) with consistent results, compared with 10 days treatment in three cell strains using real-time quantitative PCR for mRNA changes in the previously described study. ${ }^{48}$ In addition, the markers for Wnt activation are different between studies. The TCF/LEF luciferase assay in this study has been frequently used and is a reliable Wnt activation marker. Axin2 mRNA is a sensitive marker, but Dex might regulate axin2 transcription using factors independent of $\beta$-catenin and therefore might not be specific. Also, ECM proteins have different isoforms and contribute differently to TM outflow. A well-known case is FN because it has both soluble and insoluble forms, and insoluble FN is believed to have more important roles on TM outflow research. ${ }^{36}$ Therefore, immunofluorescence for both
FN isoforms was conducted in addition to Western immunoblotting to compare FN expression and deposition under different conditions.

In this study, all three GSK3 $\beta$ inhibitors showed typical biphasic dose-response curves. Among these compounds, CHIR seems to be the most potent. As described previously in this article, they are selective but not specific and may have some off-target effects. Compared with recombinant Wnt proteins, using GSK3 $\beta$ inhibitors is more convenient and potent. They are less likely to activate noncanonical Wnt signaling [which may activate the Rho/Rho-associated protein kinase (ROCK) pathway and lead to increased TM contractility] as well as interfering with receptor-ligand interactions. Also, the efficacy of recombinant Wnt proteins varies among different lots.

In a previous study, the mouse eyes were intravitreally injected with Ad5-sFRP1 (another Wnt inhibitor) together with topical application of GSK3 $\alpha$ and GSK3 $\beta$ inhibitor compound 12, and the result showed that compound 12 alleviated sFRP1-induced ocular hypertension. ${ }^{21}$ In this study, because the efficiency of ocular delivery of the three GSK3 $\beta$ inhibitors tested was unknown, the Ad5 adenoviral vector-based approach was used to express Wnt3a in the TM in a mouse model of Dex-induced ocular hypertension. $^{21,49}$ Several approaches have been established for ocular hypertension induction by GCs, including topical eyedrops ${ }^{50,51}$ systemic delivery using a minipump, ${ }^{52,53}$ and periocular injection. ${ }^{32,54}$ Among these approaches, periocular injection seems to be more convenient. Using this mouse model, a great reduction of ocular hypertension with concomitant Wnt3a expression was observed, suggesting activation of canonical Wnt signaling could be a potential therapeutic strategy for GC-induced ocular hypertension prevention and/or treatment. Recently, Dhamodaran et $\mathrm{al}^{55}$ demonstrated in vitro that another GSK3 $\beta$ inhibitor softens primary TM cells as well as inhibits the expression of ECM, cross-linkers of ECM, and inhibitors of matrix metalloproteinases. Although the changes in genes involved in ECM remodeling were not determined in that study, their roles in ocular hypertension prevention were inferred in that study. Therefore, further studies are needed to determine whether, which, and how GSK3 $\beta$ inhibitors are able to lower IOP similar to Wnt3a.

There are several models/hypotheses for GC-induced ocular hypertension, including glucocorticoid receptor- $\alpha$ (functional receptor)/glucocorticoid receptor- $\beta$ (alternatively spliced glucocorticoid receptor as a dominant negative receptor) ratio, ${ }^{3,56}$ endoplasmic reticulum stress, ${ }^{16,51}$ integrin signaling, ${ }^{57}$ and exosomes. ${ }^{58}$ Biomechanically, our published studies and other groups showed that GCs cause stiffening of TM cells, TM tissues, and TM cell-derived ECM. ${ }^{14,54}$ The current findings contribute to the existing knowledge base of GIG. Meanwhile, little is known about the underlying mechanism how Wnt signaling affects glucocorticoid receptor signaling in the TM. Studies showed that GCglucocorticoid receptor complex recruits other 
transcriptional factors and DNA/chromatin modification enzymes to facilitate transcriptional regulation. Takayama et $\mathrm{al}^{59}$ showed that glucocorticoid receptors can bind $\beta$-catenin and change the recruitment or accessibility of $\beta$-catenin at the cyclin D1 promoter in non-TM cells. The authors propose that the glucocorticoid receptor- $\beta$-catenin complex requires additional factors to regulate gene expression. Smith and Frenkel ${ }^{42}$ showed that in MC3T3-E1 cells, Dex requires histone deacetylases 1 (HDAC1) to inhibit Wnt signaling. Sharma et $\mathrm{al}^{60}$ showed that in rat hypothalamic IVB cells, Dex induces the formation of a complex involving glucocorticoid receptor, $\mathrm{MeCP} 2$, as well as DnMT3b, and HDAC1 (DnMT3b and HDAC1 are transcriptional repressors). On the basis of these reports, we hypothesize that Wnt signaling may promote the formation of a nuclear complex of $\beta$-catenin and glucocorticoid receptor, and this complex recruits DNA/histone modification enzymes that inhibit the genes regulated by glucocorticoid response elements. If this hypothesis is correct, then it will further support the potential application using Wnt activation to treat GC-induced ocular hypertension. More importantly, it may be able to suppress GCrelated adverse effects without compromising GC's therapeutic effect. Glucocorticoid receptor functions as either a transactivator (eg, via glucocorticoid response elements to up-regulate genes, such as ECM or anti-inflammatory factors) or transrepressor (eg, via negative glucocorticoid response elements to inhibit genes, such as proinflammatory factors). ${ }^{61,62}$ Patel et al ${ }^{56}$ recently showed that glucocorticoid receptor transactivation is responsible for GC-induced ocular hypertension in mouse eyes. Therefore, the approach proposed in this study may be able to transform glucocorticoid receptor from transactivators into transrepressors so that the negative glucocorticoid response element-mediated antiinflammatory effects will not be affected and may even be enhanced. Also, by selection of different cotranscriptional factors, it is likely that the glucocorticoid receptor $-\beta$-catenin complex might not affect the transcription of antiinflammatory factors, even when binding to their glucocorticoid response elements. Further research is needed to determine the molecular mechanisms.

In summary, using cell-based assays and an in vivo mouse model, we found that the canonical Wnt signaling inhibits glucocorticoid receptor signaling in the TM, further blocking GC-induced ocular hypertension. Therefore, activation of the canonical Wnt signaling pathway in the TM may be a potential therapeutic strategy for the future treatment of GIG and POAG.

\section{Author Contributions}

C.K.S. and W.M. conceived the project and designed the experiments. S.L., S.G.D., P.H.P., E.A.M., L.B.C., R.L.F., D.G.G., M.R.B., M.E.E., D.S.G., and O.U.S. recruited patients and provided clinical samples. C.K.S., N.P.R., J.D., M.P., H.C.W., and W.M. collected and processed clinical samples. V.K.R. and A.F.C. provided trabecular meshwork cells and intellectual input. N.P.R. and W.M. performed enzyme-linked immunosorbent assays. C.K.S. performed all cell-based assays, Western immunoblotting, and immunostaining. S.L.H. and W.M. conducted mouse studies. C.K.S., N.P.R., and W.M. analyzed the data. C.K.S. wrote the manuscript. C.K.S., H.C.W., L.B.C., A.F.C., V.K.R., and W.M. revised the manuscript.

\section{Supplemental Data}

Supplemental material for this article can be found at http://doi.org/10.1016/j.ajpath.2021.02.018.

\section{References}

1. Resnikoff S, Pascolini D, Etya'ale D, Kocur I, Pararajasegaram R, Pokharel GP, Mariotti SP: Global data on visual impairment in the year 2002. Bull World Health Organ 2004, 82:844-851

2. Investigators TA; The AGIS Investigators: The Advanced Glaucoma Intervention Study (AGIS): 7: the relationship between control of intraocular pressure and visual field deterioration. Am J Ophthalmol 2000, 130:429-440

3. Clark AF, Wordinger RJ: The role of steroids in outflow resistance. Exp Eye Res 2009, 88:752-759

4. Armaly MF: Effect of corticosteroids on intraocular pressure and fluid dynamics, II: the effect of dexamethasone in the glaucomatous eye. Arch Ophthalmol 1963, 70:492-499

5. Armaly MF, Becker B: Intraocular pressure response to topical corticosteroids. Fed Proc 1965, 24:1274-1278

6. Clark AF, Wilson K, de Kater AW, Allingham RR, McCartney MD: Dexamethasone-induced ocular hypertension in perfusion-cultured human eyes. Invest Ophthalmol Vis Sci 1995, 36:478-489

7. Becker B, Hahn KA: Topical corticosteroids and heredity in primary open-angle glaucoma. Am J Ophthalmol 1964, 57:543-551

8. Razeghinejad MR, Katz LJ: Steroid-induced iatrogenic glaucoma. Ophthalmic Res 2012, 47:66-80

9. Roberti G, Oddone F, Agnifili L, Katsanos A, Michelessi M, Mastropasqua L, Quaranta L, Riva I, Tanga L, Manni G: Steroidinduced glaucoma: epidemiology, pathophysiology, and clinical management. Surv Ophthalmol 2020, 65:458-472

10. Tektas OY, Lutjen-Drecoll E: Structural changes of the trabecular meshwork in different kinds of glaucoma. Exp Eye Res 2009, 88:769-775

11. Stamer WD, Acott TS: Current understanding of conventional outflow dysfunction in glaucoma. Curr Opin Ophthalmol 2012, 23:135-143

12. Ellingsen BA, Grant WM: The relationship of pressure and aqueous outflow in enucleated human eyes. Invest Ophthalmol 1971, 10: 430-437

13. Grant WM: Experimental aqueous perfusion in enucleated human eyes. Arch Ophthalmol 1963, 69:783-801

14. Raghunathan VK, Morgan JT, Park SA, Weber D, Phinney BS, Murphy CJ, Russell P: Dexamethasone stiffens trabecular meshwork, trabecular meshwork cells, and matrix. Invest Ophthalmol Vis Sci 2015, 56:4447-4459

15. Clark AF, Wilson K, McCartney MD, Miggans ST, Kunkle M, Howe W: Glucocorticoid-induced formation of cross-linked actin networks in cultured human trabecular meshwork cells. Invest Ophthalmol Vis Sci 1994, 35:281-294

16. Kasetti RB, Maddineni P, Millar JC, Clark AF, Zode GS: Increased synthesis and deposition of extracellular matrix proteins leads to endoplasmic reticulum stress in the trabecular meshwork. Sci Rep 2017, 7:14951 
17. Zhang X, Ognibene CM, Clark AF, Yorio T: Dexamethasone inhibition of trabecular meshwork cell phagocytosis and its modulation by glucocorticoid receptor beta. Exp Eye Res 2007, 84:275-284

18. Bermudez JY, Webber HC, Brown B, Braun TA, Clark AF, Mao W: A comparison of gene expression profiles between glucocorticoid responder and non-responder bovine trabecular meshwork cells using RNA sequencing. PLoS One 2017, 12:e0169671

19. Mao W, Wordinger RJ, Clark AF: Focus on molecules: SFRP1. Exp Eye Res 2010, 91:552-553

20. Mao W, Millar JC, Wang WH, Silverman SM, Liu Y, Wordinger RJ, Rubin JS, Pang IH, Clark AF: Existence of the canonical Wnt signaling pathway in the human trabecular meshwork. Invest Ophthalmol Vis Sci 2012, 53:7043-7051

21. Wang WH, McNatt LG, Pang IH, Millar JC, Hellberg PE, Hellberg MH, Steely HT, Rubin JS, Fingert JH, Sheffield VC, Stone EM, Clark AF: Increased expression of the WNT antagonist sFRP-1 in glaucoma elevates intraocular pressure. J Clin Invest 2008, 118:1056-1064

22. Mao W, Rubin JS, Anoruo N, Wordinger RJ, Clark AF: SFRP1 promoter methylation and expression in human trabecular meshwork cells. Exp Eye Res 2012, 97:130-136

23. Pang IH, Shade DL, Clark AF, Steely HT, DeSantis L: Preliminary characterization of a transformed cell strain derived from human trabecular meshwork. Curr Eye Res 1994, 13:51-63

24. Jain A, Wordinger RJ, Yorio T, Clark AF: Spliceosome protein (SRp) regulation of glucocorticoid receptor isoforms and glucocorticoid response in human trabecular meshwork cells. Invest Ophthalmol Vis Sci 2012, 53:857-866

25. Gasull X, Castany M, Castellanos A, Rezola M, Andres-Bilbe A, Canut MI, Estevez R, Borras T, Comes N: The LRRC8-mediated volume-regulated anion channel is altered in glaucoma. Sci Rep 2019, 9:5392

26. Chen W, Yang X, Fang J, Zhang Y, Zhu W, Yang X: Rho-associated protein kinase inhibitor treatment promotes proliferation and phagocytosis in trabecular meshwork cells. Front Pharmacol 2020, 11:302

27. Keller KE, Bhattacharya SK, Borras T, Brunner TM, Chansangpetch S, Clark AF, et al: Consensus recommendations for trabecular meshwork cell isolation, characterization and culture. Exp Eye Res 2018, 171:164-173

28. Martens JW, Sieuwerts AM, Bolt-deVries J, Bosma PT, Swiggers SJ, Klijn JG, Foekens JA: Aging of stromal-derived human breast fibroblasts might contribute to breast cancer progression. Thromb Haemost 2003, 89:393-404

29. Naujok O, Lentes J, Diekmann U, Davenport C, Lenzen S: Cytotoxicity and activation of the Wnt/beta-catenin pathway in mouse embryonic stem cells treated with four GSK3 inhibitors. BMC Res Notes 2014, 7:273

30. Mao W, Wordinger RJ, Clark AF: Functional analysis of diseaseassociated polymorphism LRP5.Q89R. Mol Vis 2011, 17:894-902

31. Wang WH, Millar JC, Pang IH, Wax MB, Clark AF: Noninvasive measurement of rodent intraocular pressure with a rebound tonometer. Invest Ophthalmol Vis Sci 2005, 46:4617-4621

32. Patel GC, Phan TN, Maddineni P, Kasetti RB, Millar JC, Clark AF, Zode GS: Dexamethasone-induced ocular hypertension in mice: effects of myocilin and route of administration. Am J Pathol 2017, 187: 713-723

33. Armaly MF: Effect of corticosteroids on intraocular pressure and fluid dynamics, I: the effect of dexamethasone in the normal eye. Arch Ophthalmol 1963, 70:482-491

34. Johnson D, Gottanka J, Flugel C, Hoffmann F, Futa R, Lutjen-Drecoll E: Ultrastructural changes in the trabecular meshwork of human eyes treated with corticosteroids. Arch Ophthalmol 1997, 115:375-383

35. White ES, Baralle FE, Muro AF: New insights into form and function of fibronectin splice variants. J Pathol 2008, 216:1-14

36. Medina-Ortiz WE, Belmares R, Neubauer $\mathrm{S}$, Wordinger RJ, Clark AF: Cellular fibronectin expression in human trabecular meshwork and induction by transforming growth factor- $\beta 2$. Invest Ophthalmol Vis Sci 2013, 54:6779-6788
37. Sihota R, Konkal VL, Dada T, Agarwal HC, Singh R: Prospective, longterm evaluation of steroid-induced glaucoma. Eye (Lond) 2008, 22:26-30

38. Achiou Z, Toumi H, Touvier J, Boudenot A, Uzbekov R, Ominsky MS, Pallu S, Lespessailles E: Sclerostin antibody and interval treadmill training effects in a rodent model of glucocorticoidinduced osteopenia. Bone 2015, 81:691-701

39. Yao W, Dai W, Jiang L, Lay EY, Zhong Z, Ritchie RO, Li X, Ke H, Lane NE: Sclerostin-antibody treatment of glucocorticoid-induced osteoporosis maintained bone mass and strength. Osteoporos Int 2016, 27:283-294

40. Chen W, Tang H, Liu X, Zhou M, Zhang J, Tang K: Dickkopf1 upregulation induced by a high concentration of dexamethasone promotes rat tendon stem cells to differentiate into adipocytes. Cell Physiol Biochem 2015, 37:1738-1749

41. Naito M, Omoteyama K, Mikami Y, Takahashi T, Takagi M: Inhibition of Wnt/beta-catenin signaling by dexamethasone promotes adipocyte differentiation in mesenchymal progenitor cells, ROB-C26. Histochem Cell Biol 2012, 138:833-845

42. Smith E, Frenkel B: Glucocorticoids inhibit the transcriptional activity of LEF/TCF in differentiating osteoblasts in a glycogen synthase kinase-3beta-dependent and -independent manner. J Biol Chem 2005, 280:2388-2394

43. Wallace K, Marek CJ, Hoppler S, Wright MC: Glucocorticoiddependent transdifferentiation of pancreatic progenitor cells into hepatocytes is dependent on transient suppression of WNT signalling. J Cell Sci 2010, 123:2103-2110

44. Zhou H, Mehta S, Srivastava SP, Grabinska K, Zhang X, Wong C, Hedayat A, Perrotta P, Fernandez-Hernando C, Sessa WC, Goodwin JE: Endothelial cell-glucocorticoid receptor interactions and regulation of Wnt signaling. JCI Insight 2020, 5: e131384

45. Kwon HS, Lee HS, Ji Y, Rubin JS, Tomarev SI: Myocilin is a modulator of Wnt signaling. Mol Cell Biol 2009, 29:2139-2154

46. Stone EM, Fingert JH, Alward WL, Nguyen TD, Polansky JR, Sunden SL, Nishimura D, Clark AF, Nystuen A, Nichols BE, Mackey DA, Ritch R, Kalenak JW, Craven ER, Sheffield VC: Identification of a gene that causes primary open angle glaucoma. Science 1997, 275:668-670

47. Yuan Y, Call MK, Yuan Y, Zhang Y, Fischesser K, Liu CY, Kao WW: Dexamethasone induces cross-linked actin networks in trabecular meshwork cells through noncanonical wnt signaling. Invest Ophthalmol Vis Sci 2013, 54:6502-6509

48. Ahadome SD, Zhang C, Tannous E, Shen J, Zheng JJ: Small-molecule inhibition of Wnt signaling abrogates dexamethasone-induced phenotype of primary human trabecular meshwork cells. Exp Cell Res 2017, 357:116-123

49. Patel AK, Park KK, Hackam AS: Wnt signaling promotes axonal regeneration following optic nerve injury in the mouse. Neuroscience 2017, 343:372-383

50. Faralli JA, Dimeo KD, Trane RM, Peters D: Absence of a secondary glucocorticoid response in C57BL/6J mice treated with topical dexamethasone. PLoS One 2018, 13:e0192665

51. Zode GS, Sharma AB, Lin X, Searby CC, Bugge K, Kim GH, Clark AF, Sheffield VC: Ocular-specific ER stress reduction rescues glaucoma in murine glucocorticoid-induced glaucoma. J Clin Invest 2014, 124:1956-1965

52. Overby DR, Bertrand J, Tektas OY, Boussommier-Calleja A, Schicht M, Ethier CR, Woodward DF, Stamer WD, Lutjen-Drecoll E: Ultrastructural changes associated with dexamethasone-induced ocular hypertension in mice. Invest Ophthalmol Vis Sci 2014, 55: 4922-4933

53. Whitlock NA, McKnight B, Corcoran KN, Rodriguez LA, Rice DS: Increased intraocular pressure in mice treated with dexamethasone. Invest Ophthalmol Vis Sci 2010, 51:6496-6503

54. Li G, Lee C, Agrahari V, Wang K, Navarro I, Sherwood JM, Crews K, Farsiu S, Gonzalez P, Lin CW, Mitra AK, Ethier CR, Stamer WD: In vivo measurement of trabecular meshwork stiffness in 
a corticosteroid-induced ocular hypertensive mouse model. Proc Natl Acad Sci U S A 2019, 116:1714-1722

55. Dhamodaran K, Baidouri H, Sandoval L, Raghunathan V: Wnt activation after inhibition restores trabecular meshwork cells toward a normal phenotype. Invest Ophthalmol Vis Sci 2020, 61:30

56. Patel GC, Millar JC, Clark AF: Glucocorticoid receptor transactivation is required for glucocorticoid-induced ocular hypertension and glaucoma. Invest Ophthalmol Vis Sci 2019, 60: 1967-1978

57. Filla MS, Faralli JA, Peotter JL, Peters DM: The role of integrins in glaucoma. Exp Eye Res 2017, 158:124-136

58. Dismuke WM, Klingeborn M, Stamer WD: Mechanism of fibronectin binding to human trabecular meshwork exosomes and its modulation by dexamethasone. PLoS One 2016, 11:e0165326
59. Takayama S, Rogatsky I, Schwarcz LE, Darimont BD: The glucocorticoid receptor represses cyclin D1 by targeting the Tcf-betacatenin complex. J Biol Chem 2006, 281:17856-17863

60. Sharma D, Bhave S, Gregg E, Uht R: Dexamethasone induces a putative repressor complex and chromatin modifications in the $\mathrm{CRH}$ promoter. Mol Endocrinol 2013, 27:1142-1152

61. Uhlenhaut NH, Barish GD, Yu RT, Downes M, Karunasiri M, Liddle C, Schwalie P, Hubner N, Evans RM: Insights into negative regulation by the glucocorticoid receptor from genome-wide profiling of inflammatory cistromes. Mol Cell 2013, 49:158-171

62. Miyata M, Lee JY, Susuki-Miyata S, Wang WY, Xu H, Kai H, Kobayashi KS, Flavell RA, Li JD: Glucocorticoids suppress inflammation via the upregulation of negative regulator IRAK-M. Nat Commun 2015, 6:6062 